\title{
The Challenging Pharmacokinetics of Mitotane: An Old Drug in Need of New Packaging
}

\author{
Malik Salman Haider $^{1} \cdot$ Taufiq Ahmad $^{2}$ • Jürgen Groll ${ }^{2}$. Oliver Scherf-Clavel ${ }^{3}$. Matthias Kroiss ${ }^{4,6}$. \\ Robert Luxenhofer ${ }^{1,5}$ (1)
}

Accepted: 24 June 2021

(c) The Author(s) 2021, corrected publication 2021

\begin{abstract}
Adrenocortical carcinoma (ACC) is a malignant tumor originating from the adrenal gland cortex with a heterogeneous but overall dismal prognosis in advanced stages. For more than 50 years, mitotane has remained a cornerstone for the treatment of ACC as adjuvant and palliative therapy. It has a very poor aqueous solubility of $0.1 \mathrm{mg} / \mathrm{l}$ and high partition coefficient in octanol/water $\left(\log P\right.$ ) value of 6 . The commercially available dosage form is $500 \mathrm{mg}$ tablets (Lysodren ${ }^{\circledR}$ ). Even at doses up to $6 \mathrm{~g} /$ day (12 tablets in divided doses) for several months, $>50 \%$ patients do not achieve therapeutic plasma concentration $>14 \mathrm{mg} / \mathrm{l}$ due to poor water solubility, large volume of distribution and inter/intra-individual variability in bioavailability. This article aims to give a concise update of the clinical challenges associated with the administration of high-dose mitotane oral therapy which encompass the issues of poor bioavailability, difficult-to-predict pharmacokinetics and associated adverse events. Moreover, we present recent efforts to improve mitotane formulations. Their success has been limited, and we therefore propose an injectable mitotane formulation instead of oral administration, which could bypass many of the main issues associated with high-dose oral mitotane therapy. A parenteral administration of mitotane could not only help to alleviate the adverse effects but also circumvent the variable oral absorption, give better control over therapeutic plasma mitotane concentration and potentially shorten the time to achieve therapeutic drug plasma concentrations considerably.
\end{abstract}

\section{Plain Language summary}

Mitotane as tablet form is currently the standard treatment for adrenocortical carcinoma. It has been used for 5 decades but suffers from highly variable responses in patients, subsequent adverse effects and overall lower response rate. This can be fundamentally linked to the exceedingly poor water solubility of mitotane itself. In terms of enhancing water solubility, a few research groups have attempted to develop better formulations of mitotane to overcome the issues associated with tablet dosage form. However, the success rate was limited, and these formulations did not make it into the clinics. In this article, we have comprehensively reviewed the properties of these formulations and discuss the reasons for their limited utility. Furthermore, we discuss a recently developed mitotane nanoformulation that led us to propose a novel approach to mitotane

Matthias Kroiss

matthias.kroiss@med.lmu.de

Robert Luxenhofer

robert.luxenhofer@helsinki.fi

1 Functional Polymer Materials, Chair for Chemical Technology of Material Synthesis, Institute for Functional Materials and Biofabrication, Faculty of Chemistry and Pharmacy, University of Würzburg, Röntgenring 11, 97070 Würzburg, Germany

2 Department of Functional Materials in Medicine and Dentistry, Institute for Functional Materials and Biofabrication, and Bavarian Polymer Institute University of Würzburg, Pleicherwall 2, 97070 Würzburg, Germany
3 Institute for Pharmacy and Food Chemistry, University of Würzburg, 97074 Würzburg, Germany

4 Department of Internal Medicine I, Division of Endocrinology/Diabetology, University Hospital Würzburg, Oberdürrbacher Str. 6, 97080 Würzburg, Germany

5 Soft Matter Chemistry, Department of Chemistry and Helsinki Institute of Sustainability Science, Faculty of Science, University of Helsinki, PB 55, 00014 Helsinki, Finland

6 Present Address: Medizinische Klinik und Poliklinik IV, LMU Klinikum München, Ziemssenstr. 1, 80336 Munich, Germany 
therapy, where intravenous delivery supplements the standard oral administration. With this article, we combine the current state of knowledge as a single piece of information about the various problems associated with the use of mitotane tablets, and herein we postulate the development of a new injectable mitotane formulation, which can potentially circumvent the major problems associated to mitotane's poor water solubility.

\section{Key Points}

Mitotane is a drug of choice for cancer of the adrenal gland. It is administered in tablet dosage form with the very high dose of 4-6 g/day.

Because of poor water solubility and low bioavailability, mitotane has a unpredictable pharmacokinetic profile resulting in high inter-/intra-individual variability and severe adverse effects.

It is hypothesized that the transformation of oral mitotane to an injectable form could potentially circumvent the major problems while providing better control over mitotane plasma concentrations and overall improving the therapeutic outcomes.

\section{Introduction}

Advancement in combinatorial chemistries, automated synthesis and high-throughput screening in medicinal chemistry led to the development of many hits and leads as drug molecules. Unfortunately, poor intrinsic aqueous solubility is common to both synthetic pharmacophores and pharmacologically active natural compounds [1]. According to an estimate, $40 \%$ of the drugs on the market and $90 \%$ of the drugs in the development pipeline are highly hydrophobic [2-4]. For an orally administered medicine, the oral bioavailability is a crucial characteristic in a target product profile. Low aqueous solubility of the active pharmaceutical ingredient is a significant risk factor for poor oral absorption because in most cases absorption in the aqueous environment of the gastrointestinal tract (GIT) requires soluble single molecules or alternative formulations from which the drug molecules can be absorbed into systemic circulation [5]. Accordingly, formulation plays an essential role in controlling the rate and extent of absorption of such drug molecules from the GIT. For the molecules with aqueous solubility $<1 \mathrm{mg} / \mathrm{l}$, the bioavailability from a conventional tablet formulation may be unacceptable [6]. Various strategies have been developed to improve the delivery of biopharmaceutical classification system (BCS) class II (low solubility and high permeability) and class IV drugs (low solubility and low permeability) [1]. Hence, for numerous drugs and drug candidates, the development of appropriate formulation is of paramount importance to achieve therapeutic plasma concentrations with limited side effects.

In the pool of hydrophobic drugs, mitotane, being a drug of choice for adrenocortical carcinoma (ACC) [7, 8], also suffers from intrinsic poor aqueous solubility and low bioavailability $[9,10]$. Recently, Corso et al. published a review which has provided a systematic details about the poor pharmacokinetics and pharmacodynamics of mitotane [11]. Contrarily, our article focuses more on the biopharmaceutics of mitotane with a special emphasis on development of new formulations and dosage forms. In particular, we highlighted the properties and limitations of the tablet dosage form that is currently available on the market and current therapy principles including high-dose oral mitotane therapy with the focus on disadvantages and adverse effects associated with this regimen. In addition, we review the available data about its (population) pharmacokinetics profile and mainly discuss the published pharmaceutical advancements of mitotane formulations. We also provide an evidence-based concrete hypothesis that transforming the mitotane dosage form from oral to injectable will significantly improve the therapeutic outcomes while minimizing the adverse effects.

A bibliographical search made in the "PubMed" database using "mitotane" as the only search term resulting in around 800 publications from 2000 until March 2021. In line with the aim of this article, the search results were categorized into four bins: (1) mitotane delivery, (2) ACC treatment/clinical reports, (3) pharmacokinetics, pharmacodynamics and in vitro testing, and (4) others (Fig. 1). Apparently, the number of articles about mitotane are increasing every year but mitotane's poor aqueous solubility and low bioavailability are overlooked and rarely addressed (Fig 1, red sections in each bar). Overall, only ten articles were related to mitotane delivery, which are discussed in the next sections.

\section{Adrenocortical Carcinoma}

ACC is the primary malignancy of the adrenal cortex of the adrenal gland. It has an estimated incidence of 0.5-2 new cases per 1 million people each year $[12,13]$ with an overall 4-year survival rate of $<50 \%[14,15]$. In approximately $60 \%$ of the cases, ACC is capable of secreting adrenal steroid hormones, which may lead to Cushing's syndrome, feminization or virilization and is associated with serious morbidity 


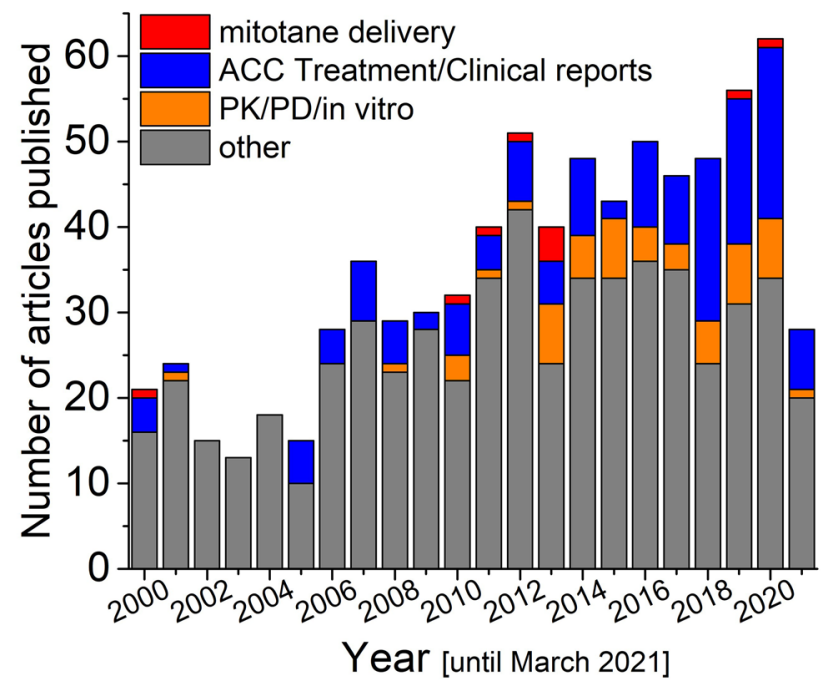

Fig. 1 Number of articles published per year using the search string "mitotane" (pubmed.org) which were manually categorized into four thematic focus areas (color coding): mitotane delivery, adrenocortical carcinoma (ACC), pharmacokinetics/pharmacodynamics (PK/ $\mathrm{PD} / \mathrm{In}$ vitro) and others. Importantly, red sections in each bar indicate the studies dealing with mitotane delivery in the context of solubility enhancement or delivery

that requires active management [16-18]. The patients with non-functional ACC present clinically with abdominal or flank pain and local tumor growth/metastasis or are diagnosed incidentally upon cross-sectional imaging conducted for other reasons ("incidentaloma"). The understanding of the molecular events underlying the development of ACC has improved in recent years [19], but is still not satisfactory. The two most frequent alterations observed in ACC so far are overexpression of IGF-2 [20,21] and constitutive activation of the $\mathrm{Wnt} / \beta$-catenin pathway [22-24]. Complete surgical resection of localized ACC is the only therapy with a curative intent. Indeed, median survival in patients with unresectable tumors or incomplete tumor resection is only 12-15 months [25]. Major advances in the field arose from collaborative research networks such as the European Network for the Study of Adrenal Tumors (ENSAT) and International ACC Conferences held since 2003 [26, 27]. These efforts led to harmonized diagnostic workups and a new staging classification and attempted to improve therapeutic options through international phase III clinical trials [17, 27-29].

\section{Mitotane}

Mitotane has often been termed an adrenolytic drug which implicates tissue specificity of its action for the adrenal cortex. Mitotane-induced adrenocortical cell death has been firmly established in vitro. On the other hand, the recovery of adrenal cortex function is common after discontinuation of mitotane suggesting that in vivo viable adrenal cortex cells persist. Beyond a cytotoxic effect of mitotane, inhibition of steroid cell synthesis is a key event that is clinically exploited.

Chemically, mitotane has initially been discovered as a by-product of the bulk synthesis of the insecticide dichlorodiphenyl-trichloroethane (DDT) [30, 31]. Mitotane is 1,1-dichloro-2-(o-chlorophenyl)-2-(p-chlorophenyl)ethane $\left(\mathrm{o}, \mathrm{p}^{\prime}-\mathrm{DDD}\right)$ and physically characterized by a very poor aqueous solubility $(0.1 \mathrm{mg} / \mathrm{l})$, a very high partition coefficient in octanol/water $(\log P)$ of 6 [9] and poor oral bioavailability of $30-40 \%$ [10, 32]. Mitotane is the only drug approved by the Food and Drug Administration (FDA) and European Medicine Agency (EMA) for the treatment of ACC $[7,8,26]$. It was introduced for the treatment of ACC more than 50 years ago by Cueto et al. [30, 31] and used as adjuvant therapy and palliative treatment $[14,33$, 34]. Depending upon the staging and grading of ACC, various treatment strategies can be adopted in many of which mitotane has remained an integral part (Fig. 2) [17]. This is reflected by the current ACC guideline that emphasizes its role as a monotherapy and as a combination partner in chemotherapy protocols $[17,18]$.

Mitotane is available in tablet dosage form under the trade name Lysodren ${ }^{\circledR}$, administered as a racemic mixture with an enantiomeric ratio of 1 (Fig. 3). It is marketed in Europe by HRA Pharma, Paris, France, and in the US by BristolMyers Squibb, Princeton, NJ. The excipients in mitotane tablets are microcrystalline cellulose, poly(ethylene glycol) (PEG) 3350, silicon dioxide and starch. Based on the low prevalence of the disease ( 0.1 in 10,000 persons), in 2002, the European commission granted orphan designation (EU/3/2/102) to Laboratories HRA Pharma, France, for mitotane for the treatment of ACC [35, 36]; at that time, mitotane was already marketed in the US and Canada. At the end of market exclusivity (period of 12 years) in Europe, this product was subsequently withdrawn from the community register of designated orphan medicinal products in 2014 [37]. Despite severe safety issues, mitotane is the only drug of choice for ACC [14, 16, 38] 


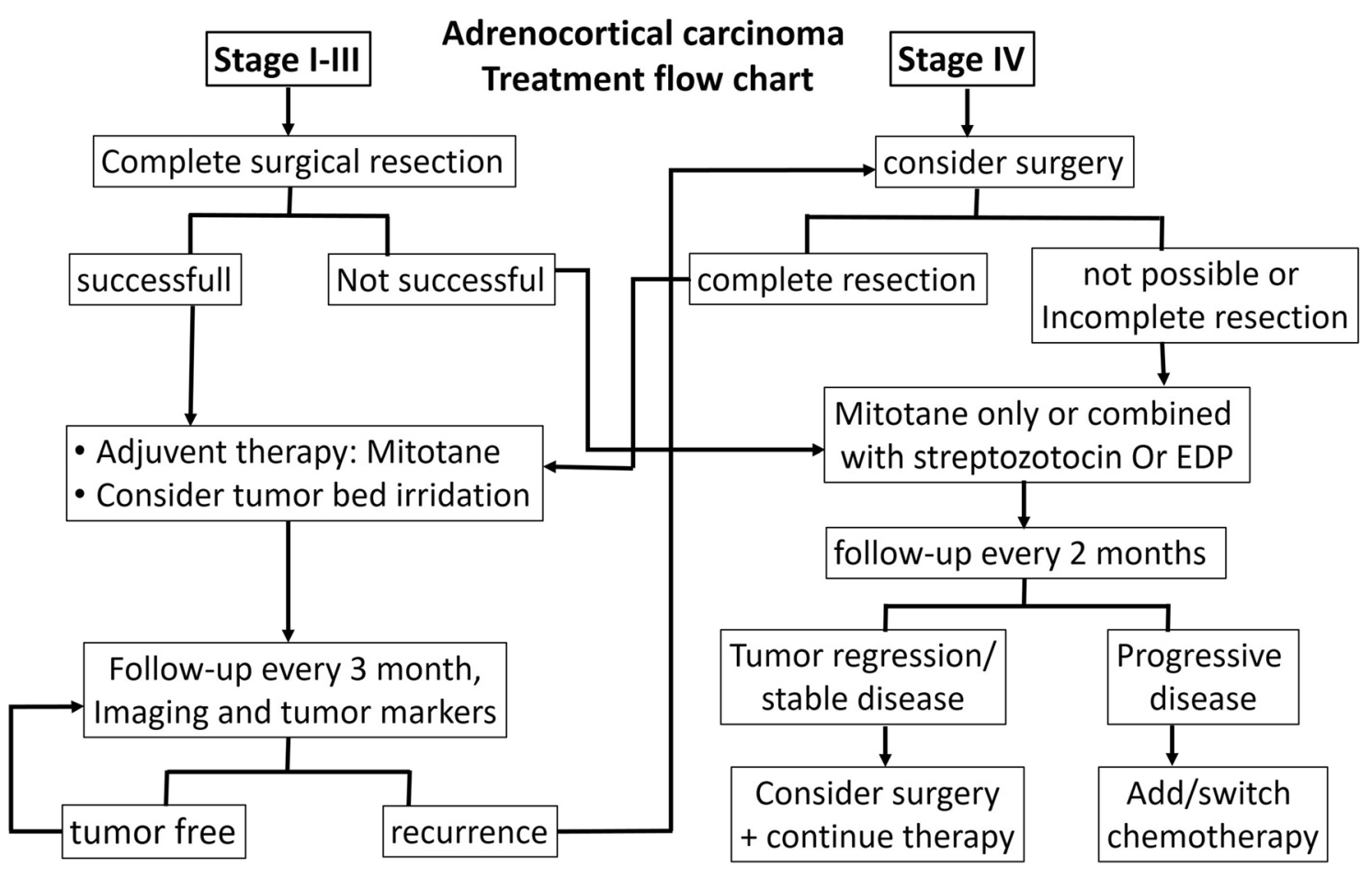

Fig. 2 Treatment flow chart for patients with adrenocortical carcinoma. EDP etoposide (E), doxorubicin (D) and cisplatin (P). Reprinted with permission from [17]. Copyright 2009 Elsevier.<smiles>N[R10]([O-])(O)O[Na]</smiles>

(R)-(+)-o, p'-DDD<smiles>ClC(Cl)(Cl)C1CC1</smiles><smiles>ClC12CCC(C1)C2</smiles><smiles>Cc1ccc(P([O])[Pb])cc1</smiles>

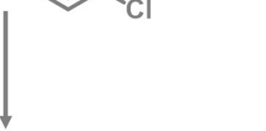

$0, p^{\prime}-D D D$

CYT-P450

$\mathrm{NADPH}, \mathrm{O}_{2}$ beta hydroxylation<smiles>Clc1ccc(C(c2ccccc2Cl)C(Cl)Cl)cc1</smiles>

(S)-(-)-o, $p^{\prime}-D D D$

Mitotane is administered as racemic mixture with two enantiomeric forms

Fig. 3 Schematic representation of mitotane metabolism [59, 60, 6567]. $p, p^{\prime}-D D T \mathrm{p}, \mathrm{p}^{\prime}$ dichlorodiphenyl-trichloroethane, $o, p^{\prime}-D D D$ o, $\mathrm{p}^{\prime}-$ dichlorodiphenyl-dichloroethane, $o, p^{\prime}-D D E \quad 0, \mathrm{p}^{\prime}$-dichlorodiphenyl-

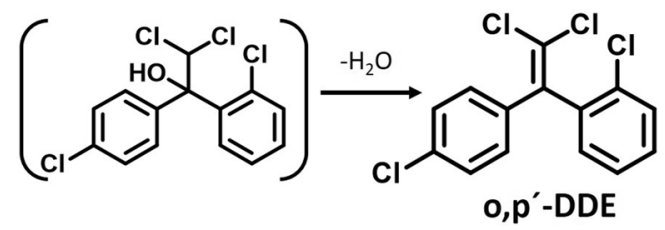<smiles>C#CCc1cc(C(C(=O)Cl)c2ccccc2Cl)ccc1Cl</smiles><smiles>C#CCOc1ccccc1C(C(=O)O)(c1ccccc1)c1ccc(Cl)cc1</smiles>

(undergo renal excretion) dichloroethene, o, $p^{\prime}$-DDAC o, $\mathrm{p}^{\prime}$-dichlorodiphenyl-acyl chloride, $o, p^{\prime}-D D A$ o, $\mathrm{p}^{\prime}$-dichlorodiphenyl-acetic acid 


\subsection{Mechanism of Action}

Astonishingly, 50 years after the introduction of mitotane into the clinics, many uncertainties about mitotane's mechanism of action, pharmacokinetics, biotransformation and treatment regimens remain, fueling an ongoing debate about its actual efficacy [39]. Despite efforts by several groups using multiple technical approaches including assessment of genome-wide gene expression [40] and proteome change [41], the actual target of mitotane remains unclear. Mitotane has a profound effect on steroidogenesis, which has been associated with the inhibition of mitochondrial cytochrome p450-dependent enzymes but the specific underlying mechanism is not fully understood [42, 43]. Involvement of mitochondria has been suggested by the analysis of mitochondrial protein expression [44], respiratory chain activity and morphofunctional features [45]. Recently, Sbiera et al. identified sterol- $O$-acyltransferase 1 (SOAT1) to be critically important and suggested it to be the key molecular target of mitotane. SOAT1 is responsible for the production of esterified cholesterol, which can protect the adrenal cells from the damaging effect of free cholesterol. In vitro biologic studies in ACC cell lines (NCI-H295) revealed that mitotane causes a rapid onset of endoplasmic reticulum (ER) stress, which in turn causes protein misfolding in ER, resulting in a signaling cascade that limits the effects of ER stress. This situation may lead to accumulation of toxic lipids inside ACC cells. The downstream signal transduction by the ER stress pathway through accumulation of toxic lipids was described for the first time as a potential underlying mechanism of action of an anti-cancer drug (particularly mitotane). This cascade leads to the inhibition of SOAT1, cholesterol ester depletion and increase of free cholesterol in NCI-H295 cell lines $[46,47]$. Recently, the same group questioned the relevance of SOAT1 as the only drug target by demonstrating lack of association between SOAT1 protein expression in ACC tissue and treatment response [48, 49] while others reported its relevance [50]. Hence, the specific underlying mechanism of action is not fully understood but further highlights, can be found in selected articles [11, 19, 38, 51-53].

\subsection{Pharmacokinetics}

Unfortunately, there is very little information available about the pharmacokinetics of mitotane, and available studies are small and sometimes contradictory. The initial pharmacokinetics data came from a study by Moy et al. performed in the early 1960 s with an assumption that $35-40 \%$ of an oral dose of mitotane is absorbed from the GIT [10]. The study included 18 patients with the average mitotane intake of 10 $\mathrm{g} /$ day. However, other data found absorption of 60\% [54] and dependency of mitotane absorption on daily dose [55].
Moolenaar and colleagues investigated the impact of various nutrients on the absorption of mitotane [54]. Patients were divided into five groups, and mitotane (a single dose of $2 \mathrm{~g}$ ) was administered as tablets, granules, mitotane powder with milk, chocolate and an oil emulsion, respectively. Compared to tablets and granules, mitotane administered with milk, chocolate and as an emulsion yielded significantly higher mean plasma concentrations in the first $5 \mathrm{~h}\left(C_{\max }\right.$ of 3-4 $\mathrm{mg} / \mathrm{l})$. In a long-term study including seven patients, at a total dose of $200 \mathrm{~g}$ administered over a 30-60-day period, a very long and highly variable plasma elimination half-life of 18-159 days was observed. The highest average plasma mitotane concentration $(18 \mathrm{mg} / \mathrm{l}, n=6)$ was reached after milk and lowest $(6 \mathrm{mg} / \mathrm{l})$ after tablet administration. To improve oral adrenolytic ACC therapy, Hermansson et al. performed comparative pharmacokinetic studies of the adrenocorticolytic drug 3-methylsulphonyl-DDE (3- $\mathrm{MeSO}_{2}$ DDE) and mitotane in minipigs [56]. The animals were given a single oral dose $(30 \mathrm{mg} / \mathrm{kg})$ of both drugs dissolved in corn oil by gastric intubation ( $n=5$ for each drug). Maximal plasma concentrations were obtained for both drugs within $24 \mathrm{~h}$ but two times higher for 3- $\mathrm{MeSO}_{2}$-DDE. At day $30,3-\mathrm{MeSO}_{2}$-DDE concentration was 25 -fold higher than mitotane in fats. The liver and plasma concentrations of mitotane were equal at 180 days while $3-\mathrm{MeSO}_{2}$-DDE was 18 -fold higher in liver than plasma. Mitotane had a 45 times higher clearance rate. $3-\mathrm{MeSO}_{2}$-DDE was found to be an interesting candidate for ACC; however, slow elimination might make it challenging to design appropriate dosage regimens.

Mitotane biotransformation involves two processes, i.e., alpha and beta hydroxylation (Fig. 3). Alpha hydroxylation leads to formation of inactive metabolite, i.e., o, $\mathrm{p}^{\prime}$ dichlorodiphenyl-dichloroethene (o, $\mathrm{p}^{\prime}$-DDE), while in case of beta hydroxylation, initially a reactive intermediate acyl chloride metabolite is formed, i.e., o, $\mathrm{p}^{\prime}$-dichlorodiphenylacyl chloride (o, $\mathrm{p}^{\prime}$-DDAC). With strong affinity for bionucleophiles, $o, p^{\prime}$-DDAC can cause acylation of cellular macromolecules. Within adrenal cells, this mechanism is thought to contribute to its mechanism of action [57]. This covalent bonding can be reversed by glutathione reductase [58] or will lead to a water-soluble inactive metabolite, i.e., o, $\mathrm{p}^{\prime}$ dichlorodiphenyl-acetic acid (o,p'-DDA) (Fig. 3), which may reach much higher plasma concentration compared to mitotane $[59,60]$. These metabolites are distributed into various body tissues with fat-containing tissues functioning as the major distribution compartment [61]. It appears there is no selective accumulation in the adrenals but high concentrations in the adrenals may be related to their high cholesterol content as adrenocortical cells require large amounts of cholesterol for steroidogenesis. Finnegan et al. found high levels of mitotane in adipose tissue of both rats and dogs [62]. 
After discontinuation of mitotane therapy, persistent plasma concentrations of mitotane (o, $\mathrm{p}^{\prime}$-DDD) and metabolites (o, $\mathrm{p}^{\prime}$-DDA and o, $\mathrm{p}^{\prime}$-DDE) are probably caused by their slow redistribution from fat and other tissues. The site of mitotane metabolic transformation is unknown but may include both the liver and extrahepatic tissues such as the adrenals [59] and possibly intestine [63]. Recently, Allegra et al. investigated the sex-related pharmacokinetic parameters which can also influence the outcomes of mitotane therapy. The authors found that female sex could be a risk factor for the failure of treatment. The results were supported by measurement of $o, p^{\prime}-D D D$ and o, $p^{\prime}-D D E$ in the patient's blood. In both cases, the $o, p^{\prime}$-DDD and o, $p^{\prime}$-DDE levels were lower in females (F) than males (M) (o,p'-DDD; F/M; 7.6/11.0 $\mu \mathrm{g} / \mathrm{ml}$ and o,p'-DDE; F/M; $0.37 / 0.82 \mu \mathrm{g} / \mathrm{ml}$ ). Accordingly, it was also observed that fewer female patients reached and maintained the mitotane level in therapeutic range [64].

Mitotane has also shown strong association with serum lipoproteins (LPs) $[68,69]$. It was previously hypothesized that serum LPs can act as Trojan horses which favor the entry of mitotane into ACC cells. However, later it was found that only free mitotane is therapeutically active [70]. Considering the strong association of mitotane with serum LPs, high mitotane concentration in chyle was demonstrated in a single patient suggesting absorption through chyle into the general circulation [63]. The presence of mitotane's inactive metabolites, o, $\mathrm{p}^{\prime}$-DDA and o, $\mathrm{p}^{\prime}$-DDE, in the chyle suggests mitotane biotransformation already before or during the resorption through the intestine. In the systemic circulation, the inactive metabolite o, $\mathrm{p}^{\prime}$-DDA was also found at concentrations ten times higher than mitotane [71] while o,p'-DDE was much less abundant [60, 66] (Fig. 3). Hescot et al. demonstrated that only mitotane can elicit the functional alteration in adrenal cells but not o, $\mathrm{p}^{\prime}$-DDA [71]. The presence of such high levels of o,p'-DDA in chyle and blood serum further confirms that mitotane undergoes both extrahepatic and hepatic metabolism followed by rapid renal excretion due to the comparably good aqueous solubility of $o, p^{\prime}$-DDA [65]. For further details on pharmacokinetics, the readers are referred to a very recent review by Corso and colleagues [11].

\subsection{Population Pharmacokinetics}

Population pharmacokinetics (popPK) help to understand the degree and sources of variability in drug concentration among individuals in a group of interest. Kerkhof et al. developed a popPK model which confirmed slow clearance and large volume of distribution using a three-compartmental model derived from 29 patients [72]. Assuming an oral bioavailability of $30 \%$, clearance and volume of distribution at steady state (Vss) were estimated at $0.94 \pm 0.37 \mathrm{l} / \mathrm{h}$ and $161 \pm 68 \mathrm{l} / \mathrm{kg}$ of the lean body mass, respectively. In another study, Arshad et al. developed a popPK model and found that a model that incorporates enzyme autoinduction best described the inter-individual variability IIV [73]. Mitotane is a known strong inducer of CYP3A4 potentially via pregnane $\mathrm{X}$ receptors (PXR). PXR ligands transcriptionally induce the activity of various processes in drug metabolism which in turn can also accelerate the metabolism of PXR ligands themselves (autoinduction) $[74,75]$. Thus, it was hypothesized that mitotane metabolism could also be affected by autoinduction leading to inter-individual differences in pharmacokinetics and therefore efficacy and toxicity among the patients. Retrospective data from 76 ACC patients were modeled by one-compartment pharmacokinetic model assuming an oral bioavailability of $35 \%$ leading to an estimate for the central volume of distribution $(\mathrm{Vc})$ of 60861 (95\% Cl 4743-7673 1) with a very high IIV of $77.3 \%$. Similar to Kerkhofs et al., they identified BMI as a covariate on Vc. Mitotane high-dose regimen and first TDM at day 16 of the treatment were favored by model simulations to manage mitotane toxicity. Cazaubon et al. developed a popPK model capable of estimating the probability of target attainment (PTA $\geq 14 \mathrm{mg} / \mathrm{l})$ at different mitotane daily doses up to 1500 days of exposition [32]. A one-compartment model best described the retrospectively collected data from 38 ACC patients (at an oral daily dose of 1-7.25 g/day). Due to unavailability of intravenous data, the bioavailability of mitotane was fixed to $35 \%$ knowing the fact that it is highly variable depending upon associated food intake $[54,76]$. The estimates for $\mathrm{Vc}$ and $\mathrm{Cl}$ were 89001 (95\% CI 6346-13467) and 70 1/day (95\% CI 59.3-78.6), respectively. IIV in $\mathrm{Cl}$ and Vc was moderate (29.3\%) and high (90.4\%), respectively. Their model supported a direct relationship among HDL, triglyceride (TG) and mitotane clearance. Increased HDL and TG both resulted in a reduction of $\mathrm{Cl}$. In addition, they identified a so-called latent variable influencing $\mathrm{Cl}$ of mitotane which the authors interpreted as potentially being the genotype of metabolizing enzymes. The PTA at 3 months with the doses of 3, 6, 9 and $12 \mathrm{~g}$ /day were $10 \%, 55 \%, 76 \%$ and $85 \%$, respectively. These simulations suggested that the recommended dosage regimen at initiation of therapy (2-3 $\mathrm{g} /$ day) is not optimal to achieve targeted mitotane plasma concentration. However, it must be pointed out that a high PTA in this case does not necessarily mean that the patients are within the therapeutic range (14-20 mg/l) [77-79].

The most commonly reported CYP enzymes involved in the metabolism of mitotane are CYP3A4 and CYP2B6 [80, 81]. With their recent popPK analysis, Yin et al. introduced a pharmacogenetic explanation for IIV in mitotane $\mathrm{Cl}$ [82]. Mitotane plasma concentration data and genetic information from 48 ACC patients were incorporated in a twocompartment model with first-order absorption and linear elimination. In contrast to other modeling approaches, Yin et al. did not fix oral bioavailability to an arbitrary value, but 
rather reported apparent values for pharmacokinetic parameters. Genetic variants in the genes encoding for CYP2C19 and the solute carrier organic anion transporters (SLCO) 1B1 and 1B3 were found to explain a large proportion of IIV in apparent clearance $(\mathrm{Cl} / \mathrm{F})$. Additionally, lean body weight (LBW) was a significant covariate on $\mathrm{Cl}$. Body fat was identified as a predictor of apparent volume of the central compartment $(\mathrm{Vc} / \mathrm{F})$. The estimates for $\mathrm{Cl} / \mathrm{F}$ and $\mathrm{Vc} / \mathrm{F}$ in the final model were 298 1/day (95\% CI 200.5-398.4) and 62101 (95\% CI 32,818-10,752), respectively, including large IIV for apparent volume of the peripheral compartment $(\mathrm{Vp} / F)$ and apparent inter-compartmental clearance $(Q / F)$. IIV in $\mathrm{Cl} / F$ and $\mathrm{Vc} / F$ were $43.0 \%$ and $47.2 \%$, respectively. In conclusion, the most important known sources of variability in the pharmacokinetics of mitotane seem to be body constitution (represented by LBW, fat mass or BMI), HDL and TG. Genetic variability in transporter proteins and metabolizing enzymes as well as (auto) induction of metabolizing enzymes are more recently discovered possible explanations for between-subject variability. However, there is still a large proportion of unexplained IIV. With this, to the best of our knowledge, we have summarized all the published data that dealt with the pharmacokinetics of mitotane. It is clear that pharmacokinetics of mitotane not only exhibit strong IIV, but despite mitotane being in clinical practice for decades, more detailed pharmacokinetic studies would still be required to fully understand the mitotane absorption, distribution, metabolism and excretion. Owing to the latency of action of mitotane associated with the time needed to reach the therapeutic target (14-20 mg/l) [77-79] and high IIV, it remains very challenging for the clinician to predict whether and within which time period mitotane target concentration will be reached. Hence, judgment is highly dependent on experience and remains subjective. Using the

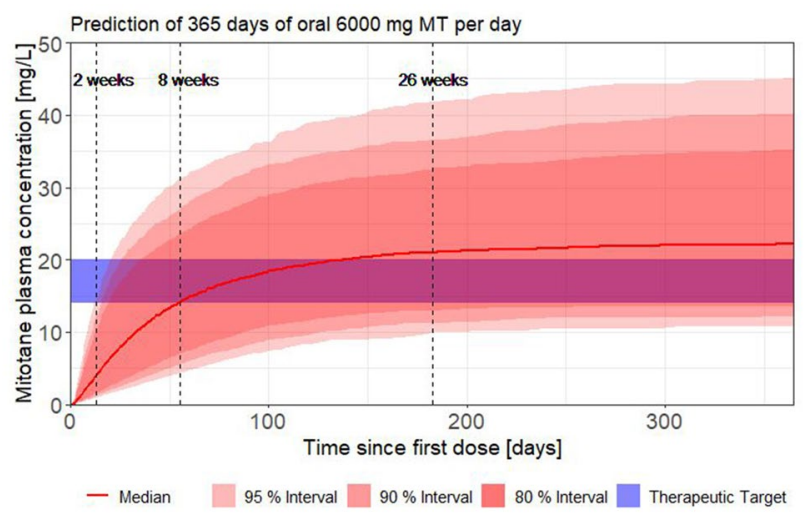

Fig. 4 Employing the model of Arshad et al. [83], the development of mitotane (MT) plasma concentrations over time was simulated using a Monte Carlo simulation; 5000 virtual patients received 1.5, 3.0 and $4.5 \mathrm{~g}$ mitotane during the first 3 days, followed by $6 \mathrm{~g} /$ day. (Reproduction of analysis of Figure 5A in [83] with longer time frame) model of Arshad et al. [83] to reproduce their analysis, the time to reach the therapeutic target of $14-20 \mathrm{mg} / \mathrm{l}$ assuming $6 \mathrm{~g}$ mitotane daily dosing (Fig. 4) while some patients could reach the target concentration as early as 2 weeks on therapy; this will not be the case even after 26 weeks in others. Median time to reach the lower therapeutic target concentration is 8 weeks according to the simulation, and a steady state is reached after about half a year in a typical patient. If higher doses are not tolerated, patients have only a minor chance to reach the target if they are not in range by week 26 . Hence, this can assist in deciding about continuation or discontinuation of mitotane after 26 weeks while considering clinical factors such as response to mitotane treatment and hormone excess.

In practice, many patients with advanced ACC receive mitotane indefinitely owing to lack of clear rules for its discontinuation. However, this might lead to severe side effects without any therapeutic effect in the case that effective serum levels are not achieved. In conclusion, all available popPK analyses reveal a large uncertainty and high degree of unexplained IIV regarding the pharmacokinetics of mitotane. As the absolute bioavailability and food effects were never thoroughly assessed because of the poor solubility and uncommonly slow pharmacokinetics, part of this uncertainty could be attributed to the oral application (i.e., first-pass metabolism, non-linear kinetics due to high mitotane concentrations in the intestine). To decrease this unacceptable degree of insecurity in this critical indication, alternative dosage forms bypassing the GIT could be beneficial.

\subsection{Clinical Dosing Regimens}

A plethora of clinical studies report that serum mitotane concentrations of $14-20 \mathrm{mg} / \mathrm{l}$ are needed for an optimal therapeutic response [77, 78, 84]. While mitotane serum concentrations below this therapeutic range are associated with a higher risk of non-response, concentrations $>20 \mathrm{mg} / \mathrm{l}$ are correlated with increased toxicity. However, in some cases, dose-limiting toxicity is reported within the therapeutic range or even below [28]. So, the administration of optimal mitotane dose depends on the patient's characteristics, which are nevertheless often the subjective experience of the individual physician. The usual recommended starting dose of mitotane is $1.5 \mathrm{~g} / \mathrm{day}$. Depending on local practice and patient characteristics, regimens with rapid dose increase to $6 \mathrm{~g} /$ day (high-dose regimen) or a low-dose regimen are used $[14,18]$. Even at high cumulative doses of $450 \mathrm{~g}$ (4-6 g/day for 3 consecutive months), more than half of the patients do not achieve the target plasma concentration, and no differences between the two regimens were observed [85]. Recently, Puglisi et al. systematically showed that mitotane therapeutic plasma concentration has a significant influence on the patient's outcomes with advanced ACC by assessing 
the time in target range (TTR: the number of months in which the mitotane concentration was $>14 \mathrm{mg} / \mathrm{l})$. The data from the 80 patients with advanced ACC not amenable to surgical resection, coming from 12 different tertiary centers in Italy between 2005-2017, were obtained from the TDM database provided by the pharmaceutical company as part of the marketing license and were retrospectively analyzed for the mitotane plasma concentration. This study gave an interesting finding that higher TTR value can be used as predictor for increased survival, corroborating the regular investigation of mitotane plasma concentrations [86].

Megerle et al. presented a study analyzing the effect of mitotane monotherapy (at median maximal dosing of $7.5 \mathrm{~g} /$ day) in 127 patients with advanced ACC [79]. All the data were retrieved from the German ACC Registry and the European Network for the Study of Adrenal Tumors (ENSAT) Registry. According to the authors, the objective response was slightly lower compared to previous reports, but mitotane monotherapy was able achieve clinical benefits. Out of 127 patients, 3 never reached a mitotane plasma concentration $>14 \mathrm{mg} / \mathrm{l}$, but objective response was observed in these patients showing that lower plasma levels do not necessarily preclude the clinical benefit. This study also suggests that patients with less aggressive tumors are good candidate for mitotane monotherapy while patients with a more aggressive clinical course would require more aggressive management. Given that there were no significant differences observed in progression-free and overall survival between patients with and without cortisol-producing ACC, the authors recommended the administration of mitotane for both functioning and non-functioning tumors. A study by Faggiano et al. further suggests that high-dose mitotane therapy with acceptable toxicity may shorten the time required to reach plasma therapeutic levels from 3-5 months to 4 weeks. This suggests that an i.v. dosage form may be very beneficial to rapidly achieve the desired plasma levels followed by oral dosing for maintenance. However, the results are based on data obtained from a small study of four ACC and two Cushing's disease patients [87].

\subsection{High-Dose Therapy's Adverse Effects}

Adverse effects of mitotane treatment are manifold and common. About $80 \%$ of the patients suffer from GIT side effects like anorexia, nausea or vomiting and in some cases diarrhea with the threshold plasma concentration of $5 \mathrm{mg} / \mathrm{l}$, meaning that these side effects start significantly before therapeutic plasma levels are reached. The most worrisome side effects involve the central nervous system (CNS), occurring in about $40 \%$ of the patients, and include ataxia, confusion, fatigue, dizziness, paresthesia and polyneuropathy [7, 26]. A reversible brain function impairment can also arise after prolonged use of high doses of mitotane. These effects appear preferentially but not exclusively in patients with mitotane plasma levels $>20 \mathrm{mg} / \mathrm{l}$. The appearance of severe CNS and GIT side effects can require the interruption of therapy until improvement of the symptoms.

Due to its adrenal toxicity, mitotane treatment induces adrenal insufficiency in virtually all patients. Changes in hepatic gamma-glutamyl-transferase levels are also commonly observed. In a few cases, serious hepatotoxicity and even liver failure have been reported [88]. Importantly, mitotane severely alters lipid metabolism. It has been known for many years that mitotane induces high LDL cholesterol production, but also HDL cholesterol and sometimes triglyceride concentrations [89] as well. The actual mechanism underlying these lipid abnormalities is unknown. Recently, it has also been observed that high dosage of mitotane causes precocious puberty [90] and encephalopathy [91, 92]. Hypothyroidism and gynecomastia have also been reported in adult patients [17, 93]. To minimize adverse drug effects, the patients require corticosteroid replacement therapy, and TDM [94] including blood testing for various markers is persistently required [18]. As ACC is a rare but aggressive tumor, the available studies cannot give a clear picture of the impact of high-dose and long-term mitotane therapy on severity and probability of adverse events. Much of the data is obtained from small case series, which limit the knowledge on adverse effects associated with chronic treatment, and thus the resulting dose-effect relationship remains unclear and unpredictable.

The maintenance of mitotane plasma concentration in the therapeutic range (14-20 mg/l) [78, 81, 84] while limiting side effects is therefore a clinical challenge. Severe adverse effects might require dose reduction or complete cessation, jeopardizing the potential therapeutic benefit while the patient's quality of life may nevertheless be impaired for prolonged periods of time as changes in dosage regimen have long lag times before they actually reflect in plasma mitotane levels. It is obvious that achievement of therapeutic mitotane plasma concentration is hampered by a combination of poor aqueous solubility and unknown, potentially highly variable bioavailability [95] and an unfavorable pharmacokinetics profile [96] resulting in long plasma equilibration time. Significant efforts have been made to offset these therapeutic limitations of mitotane therapy by investigating combination therapies.

\section{Pharmaceutical Advancements for Mitotane Formulations}

In the following chapter, we have summarized the efforts which have been undertaken to increase the aqueous solubility of mitotane, which is arguably one of the main limiting factors responsible for mitotane poor bioavailability [10]. 
As is well known for many drugs, Lin et al. showed that mitotane dissolution rate can also be increased by micronization [97], although this does not overcome the low solubility per se. The $\mathrm{O} / \mathrm{W}$ microemulsions were prepared by using water, benzyl alcohol or sodium dodecyl sulphate (SDS) at different concentrations followed by crystallization (cooling at $10^{\circ} \mathrm{C}$ ) or butyl-lactate, water, lecithin, ethanol and taurodeoxycholic followed by crystallization using solvent diffusion technique (addition of excess water). The dimensions of commercial mitotane particles were 50-200 $\mu \mathrm{m}$ in length and 30-80 $\mu \mathrm{m}$ in width, while with micronization, it was reduced to 6-14 $\mu \mathrm{m}$ in length and $1-3 \mu \mathrm{m}$ in width (recrystallization by cooling) and appeared as needles and granules of $1 \mu \mathrm{m}$ (recrystallization by solvent diffusion) (Fig. 5a, b). An increase in SDS concentration also led to morphology transition from needles to lumps. For the commercial mitotane, only $11 \%$ of the particles were dissolved after $5 \mathrm{~min}$ of dissolution while the recrystallized mitotane dissolved $44 \%$ and $55 \%$ from cooling and solvent diffusion processes, respectively (Fig. 5c). In this study, the mitotane recrystallization from microemulsion was studied in detail. The major focus was to increase the mitotane dissolution rate by this process. In vitro and in vivo experiments would be interesting to perform with this formulation but no follow-up studies have been reported by these authors.

Self-microemulsifying drug delivery systems (SMEDDS) rapidly form microemulsions upon mixing with water. They are isotropic mixtures of surfactants, co-surfactants, lipids and drugs. Attivi et al. reported SMEDDS of mitotane to reduce the long plasma equilibration time and gastrointestinal side effects by increasing the solubility and thus bioavailability of mitotane. Mitotane was dissolved in different oils and surfactants (1:16 ratio) individually or in binary and ternary mixtures [e.g., 33\% caproyl (= propylene glycol monocaprylate), 33\% Tween 20 and 33\% cremophor EL)]. Different combinations were prepared with the loading capacity
(LC) ranging between 6.25 and $25 \mathrm{wt} \%$. Drug permeation studies (with an Ussing type apparatus using jejunal mucosa of Wistar rat) showed five times higher permeation rate of oil-based SMEDDS than mitotane solution. The mitotaneSMEDDS showed the highest and fastest release after 48 $\mathrm{h}$ compared to Lysodren tablets and mitotane dissolved in capryol $(62 \pm 3 \%, 12 \pm 5 \%$ and $3 \pm 0.3 \%$, respectively) (Fig. 6a). Comparative pharmacokinetic studies were performed for mitotane-SMEDDS, Lysodren tablets and mitotane in caproyl in rabbits $(n=3)$. The plasma levels of mitotane for SMEDDS were found to be $2 \pm 1 \mathrm{mg} / \mathrm{l}$ (Fig. 6b). The relative bioavailability (in rabbits at a dose of $100 \mathrm{mg} /$ $\mathrm{kg}$ body weight as single oral administration) was increased by a factor of 3.4 for the mitotane-SMEDDS [98]. However, clinical studies would have to elucidate the impact of this formulation on GIT.

Battung and coworkers disclosed another mitotaneSMEDDS formulation, based on caproyl, propylene glycol dicaprate and polyoxyethylene sorbitan monooleate. The solubility of mitotane was found to be $0.4 \mathrm{~g}$ per gram of oily vehicle ( $\mathrm{LC}=28 \mathrm{wt} \%)$. In vivo studies were conducted in Beagle dogs $(n=3)$ in fasted and fed conditions, and the relative bioavailability was increased by a factor of $3.2 \mathrm{com}-$ pared to Lysodren tablets [99]. This increase is similar to the previously mentioned increase using milk.

Trotta et al. reported the development of a mitotane nanosuspension by solvent quenching technique to increase the surface area, thus increasing its solubility. This was achieved by first preparing an oil/water $(\mathrm{O} / \mathrm{W})$ emulsion to which excess water was added. Subsequently, the solvent was removed to obtain a nanosuspension. Mitotane was dissolved in benzyl alcohol, butyl lactate or triacetin followed by its addition into the water phase containing emulsifier (Tween 80, caprylyl-capryl glucoside or lecithin). Using high-pressure homogenization and subsequent addition of excess water, microdroplets were converted into solid
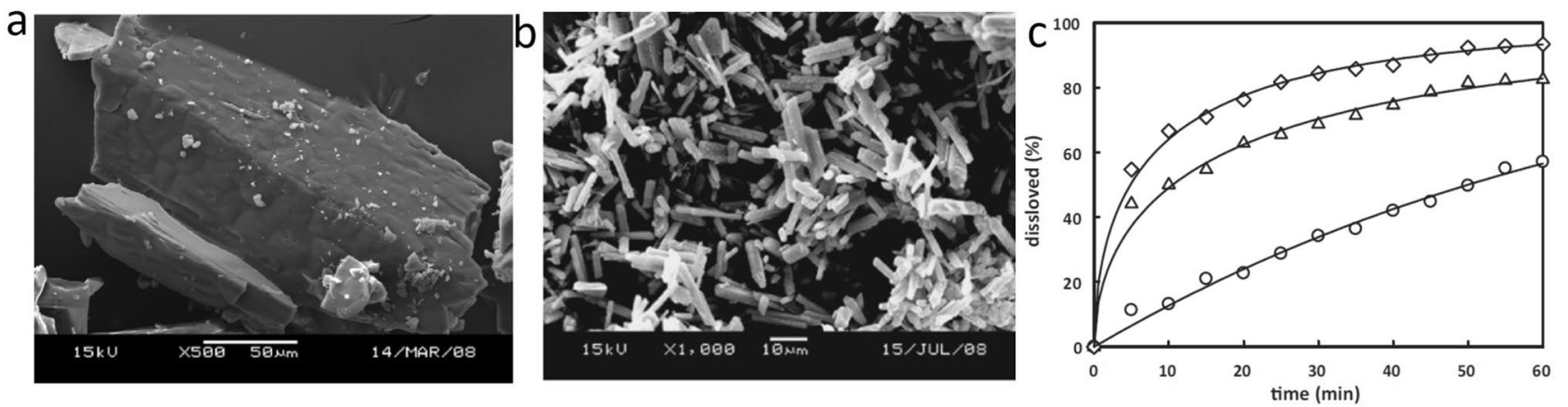

Fig. 5 a Scanning electron microscopy (SEM) images of the commercial mitotane (lump) and b recrystallized mitotane from microemulsion of water/benzyl alcohol/SDS mixtures (92.2/7.8/6) (needles). c Dissolution profile of commercial mitotane (open circle), mitotane recrystallized by cooling (open triangle) and by solvent diffusion (open diamond). SDS sodium dodecyl sulphate. Reprinted with permission from [97]. Copyright 2011 Elsevier 


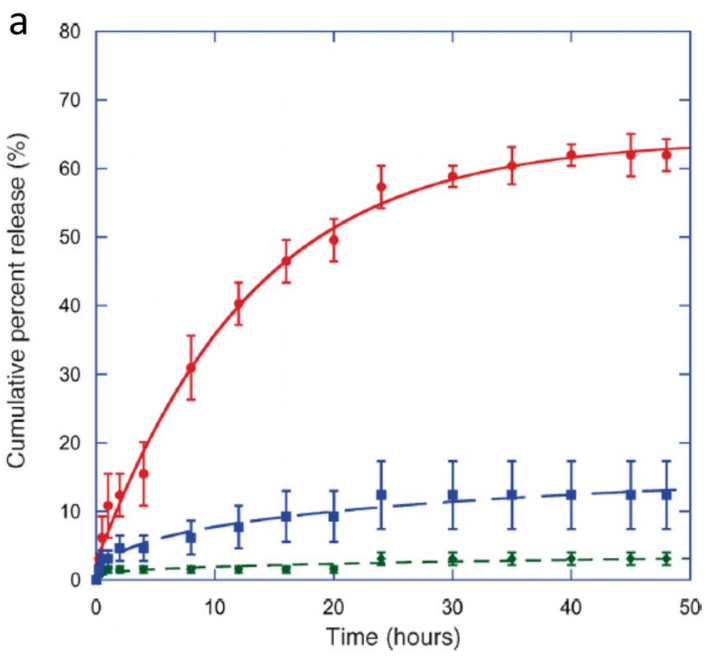

Fig. 6 a Cumulative percent of mitotane release by dialysis from SMEDDS of mitotane (red) and Lysodren tablets (blue) and from capryol (green) in phosphate buffer saline of $\mathrm{pH} 6.8(n=3)$. b Plasma concentration of mitotane after administration of $100 \mathrm{mg} / \mathrm{kg}$ (single b

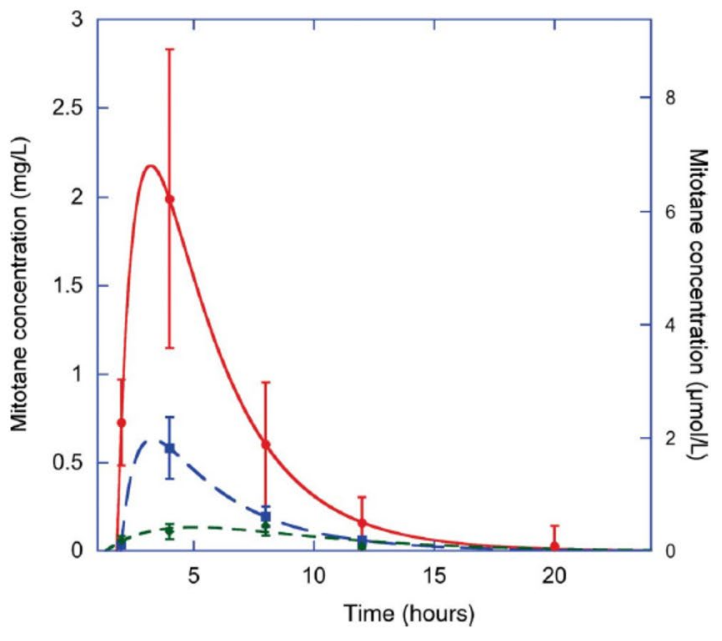

dose, orally) of mitotane SMEDDS (red), Lysodren (blue) and from capryol (green) $(n=3)$. SMEDDS self-microemulsifying drug delivery systems. Reprinted with permission from [98]. Copyright 2010 Taylor and Francis

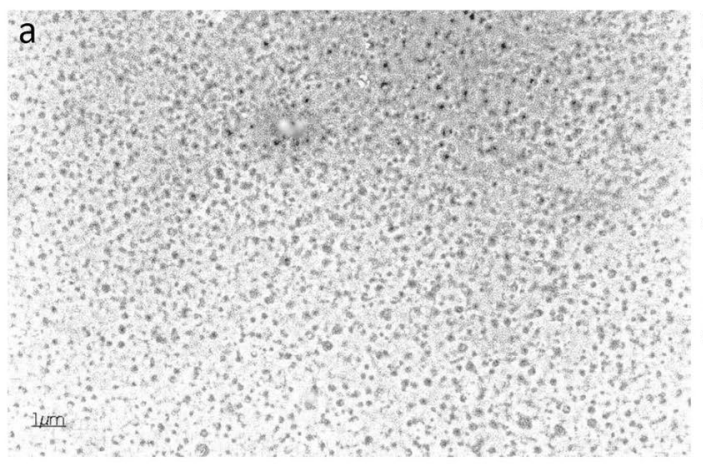

Fig. 7 a Photomicrograph of the emulsion containing butyl lactate and $0.2 \%$ Tween 80 , passed through a high pressure homogenizer. b Mitotane dissolution profile of commercial wetted product $(x)$, reference solution ( $\mathbf{\square}$ ) (water-mitotane suspension obtained by dispers-

particles. The nanosuspension obtained from butyl lactate emulsion $(47 \mathrm{mg} / \mathrm{l}$ of mitotane was dispersed in $4.85 \%$ butyl lactate in water) showed the smallest size $(80 \pm 8 \mathrm{~nm})$ and the fastest dissolution compared to commercially available mitotane [100] (Fig. 7). Similar to previous study by Lin and colleagues [97], this study also focuses only on dissolution rate enhancement of mitotane. The dissolution profile of resultant nanosuspensions was obtained at $1 \mathrm{~h}$; however, longer dissolution times at simulated GIT conditions would have given a more realistic picture. This study also lacks discussion on biologic aspects of this kind of formulation.

As previously discussed, mitotane is administered as racemic mixture of S-(-)-mitotane and R-(+)-mitotane (Fig. 3). Asp et al. demonstrated that the racemic mixture produced higher cytotoxicity than two individual enantiomers (in

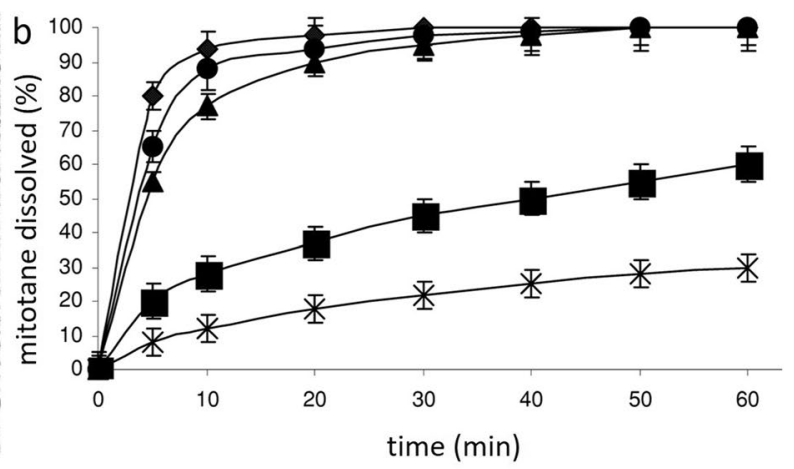

ing $10 \mathrm{mg}$ of mitotane in $1 \mathrm{ml}$ of water containing $0.01 \%$ Tween 80 ), nanosuspension obtained from emulsion of benzyl alcohol ( ), butyl lactate $(\diamond)$ and triacetin $(\boldsymbol{\Delta})$. Reprinted with permission from [100]. Copyright 2001 Elsevier

H295R cell lines). For hormone production, the effect of racemic mixture was largely the sum of two individual enantiomers at corresponding concentration. In conclusion, the authors suggested that racemic mixture is important for therapeutic efficacy of mitotane [67]. In contrast, Menaa et al. suggested the synthesis and use of mitotane (S-(-)-mitotane) enantiomer or chiral separation of racemic mixture of commercially available mitotane [101]. The latter is rationalized by studies which have shown that $\mathrm{S}-(-)$-mitotane is more potent than $\mathrm{R}-(+)$-mitotane $[102,103]$. At this point, the issue of racemic vs. enantiopure mitotane seems inconclusive. Menaa et al. also suggested the development of lipid based mitotane nanoformulations [101]. For the solubility enhancement and controlled release, Severino et al. reported a mitotane loaded solid lipid nanoparticle (SLN) 
formulation and nanostructured lipid carriers (NLCs). However, the reported loading capacity [LC $=$ (mass of drug)/ (mass of drug + mass of excipient) $\times 100 \%$ ] of $0.92 \%$ and $0.84 \%$, respectively, was very low. The formulations were only characterized for size, zeta potential and polydispersity index (PDI) (SLNs and NLCs with mean particle size of 150 and $250 \mathrm{~nm}$ and PDI of 0.2 and 0.3 , respectively). Unfortunately, no further data regarding drug release, more detailed physico-chemical characterization of formulation and in vitro experiments were provided [104].

Furthermore, Grando et al. prepared mitotane-loaded SLNs of cetyl-palmitate and NLCs of binary mixture of polyoxyethylene stearate and triglycerides of capric/caprylic acid. Tween 80 and Span 85 were used as surfactant. SLNs and NLCs had mean size of 98 and $118 \mathrm{~nm}$, but this formulation also had extremely poor drug loading of 0.05 and $0.25 \%$, respectively. The encapsulation efficiency dropped down to $<1 \%$ for both SLNs and NLCs within 15 days. Accordingly, further translational steps for this kind of mitotane formulation were not discussed [105].

In another attempt to increase the solubility and bioavailability of mitotane, Alfonsi et al. prepared the inclusion complexes of mitotane with cyclodextrin [i.e., randomly methylated- $\beta$-cyclodextrin (RAM $\beta C D)$ and dimethyl- $\beta$ cyclodextrin (DM $\beta C D)]$. The inclusion mechanism of mitotane and its isomers into the cyclodextrin were studied using a phase-solubility diagram and further analyzed by ROESY NMR spectroscopy. The results suggested that the aromatic rings in mitotane can be complexed by two DMßCD molecules (Fig. 8). A detailed analytical procedure helped to understand the inclusion mechanism but no further directions or a discussion were given on how this system can improve the bioavailability of mitotane was provided [106].

A liposomal formulation was reported using a phospholipid/mitotane combination (3.34/1) [107]. The mean

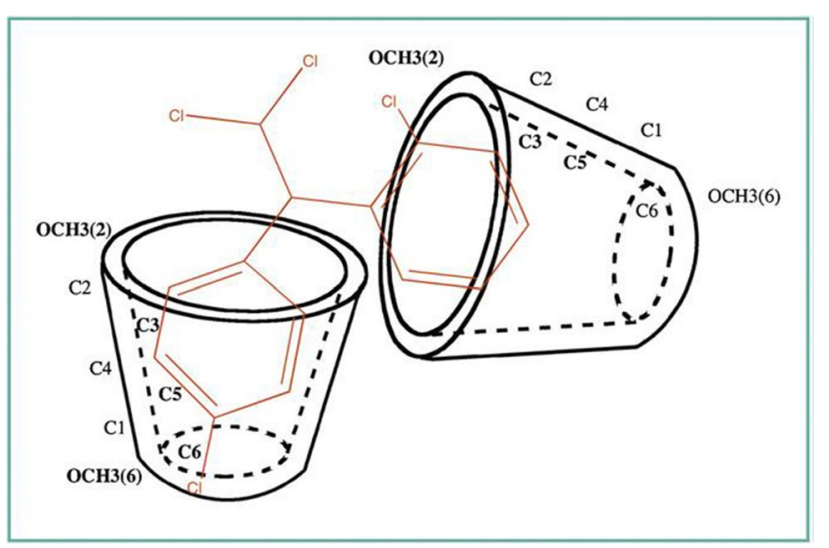

Fig. 8 Suggested molecular model of DMßCD/o,p-DDD derived from 2D-ROESY experiments. $D M \beta C D$ dimethyl- $\beta$ - cyclodextrin, $o, p^{\prime}-D D D$ o, $\mathrm{p}^{\prime}$-dichlorodiphenyl-dichloroethane. Reprinted with permission from [106]. Copyright 2013 Elsevier MASSON hydrodynamic diameter was around $1 \mu \mathrm{m}$, limiting its application to parenteral use. Liposomal mitotane (mitotane-L) was compared by dissolving mitotane with (mitotane-T) and without (mitotane-N) triglyceril ${ }^{\circledR} \mathrm{CM}$. The intestinal permeation of mitotane was evaluated using an everted gut sac model utilizing a duodenal segment of the Wistar rat intestine. The internal segment of the gut sac model showed $3.8 \%, 10 \%$ and $44.8 \%$ of mitotane for mitotane- $\mathrm{N}$, mitotane$\mathrm{T}$ and mitotane-L, respectively, showing the higher permeation capacity of mitotane-L. To compare the oral bioavailability, the dose of mitotane-L was kept five times $(2.1 \mathrm{mg})$ lower than the dose of mitotane-N and mitotane-T $(10 \mathrm{mg})$. In vivo studies in Wistar rats demonstrated the plasma concentrations at day 21 were $4.6 \mu \mathrm{g} / \mathrm{l}$ (mitotane-L), $6.4 \mu \mathrm{g} / \mathrm{l}$ (mitotane-N) and $5.3 \mu \mathrm{g} / \mathrm{l}$ (mitotane-T). The results revealed that liposomal encapsulation of mitotane was able to control the mitotane plasma concentrations and comparatively improved bioavailability even at lower doses. However, it should be noted that while some improvement is seen, the observed plasma concentrations are much lower than desired and needed.

To the best of our knowledge, only these few reports on (nanotechnology/lipid-based) alternative pharmaceutical dosage forms to improve solubility and oral bioavailability of mitotane are available. The majority of the reports solely focus on physicochemical characterization of the developed formulation without addressing biologic/clinical aspects of mitotane. The few reports that do involve in vivo studies have shortcomings in pharmacokinetics, biodistribution, efficacy and safety of the developed formulation. Additionally, no follow-up studies from any of the authors have been reported since. Therefore, it remains unclear whether these alternatives could prevent GIT toxicity caused by high-dose mitotane therapy or will bring greater benefit over pristine mitotane in preclinical studies and are capable of overcoming the limitations associated with the use of the current tablet dosage form.

\section{Mitotane: From Oral to Injectable, Potential Advantages}

Any route of administration which enables the medication to achieve the plasma drug concentration which is optimum for therapeutic response with the least adverse effects is considered the safest route [5]. Unfortunately, frequently prescribed mitotane with its commercially available tablet dosage form has serious limitations as discussed in previous sections. Compared to oral administration, direct administration to systemic circulation could reduce the IIV considerably, allowing for $100 \%$ bioavailability and rapid onset of action, and most importantly give the physician greater control over pharmacokinetics [108]. 
Generally speaking, the oral route for drug administration is the preferred and simplest route not only for patients but also for formulation scientists [109]. Nevertheless, the oral delivery of many therapeutic agents is limited by many factors. We postulate that i.v. administration of mitotane could resolve some of the major issues associated with mitotane as a therapeutic agent. To the best of our knowledge, no previous studies have ever addressed the i.v. administration of mitotane. For such administration, a suitable formulation is needed. Recently, we have reported a poly(2-oxazoline) $\mathrm{s}$ (POx)-based [110] mitotane-loaded micellar formulation developed by thin-film hydration method with very high LC of $36 \mathrm{wt} \%$ (mitotane solubility $\approx 6 \mathrm{~g} / \mathrm{l}$ ), which could potentially be explored as an injectable formulation [111]
(Fig. 9a-d). The lead amphiphile in this study was an ABA triblock copolymer, in which A and B comprised hydrophilic poly(2-methyl-2-oxazoline) (pMeOx) and moderately hydrophobic poly (2-butyl-2-oxazoline) (pBuOx) (pMeOx-bpBuOx-b-pMeOx), respectively. A detailed physico-chemical characterization of the POx-based mitotane formulations showed excellent stability despite the high loading. Moreover, the formulation can be stored as a lyophilized powder ready for redispersion, as needed. The formulation also exhibited excellent activity in vitro in $2 \mathrm{D}$ and $3 \mathrm{D}$ adrenocortical cell cultures (NCI-H295R tumor cell line). The obtained $\mathrm{IC}_{50}$ values in conventional $2 \mathrm{D}$ monolayer cell culture were comparable for mitotane dissolved in ethanol and POx micelles (15 and $19 \mu \mathrm{M}$, respectively).

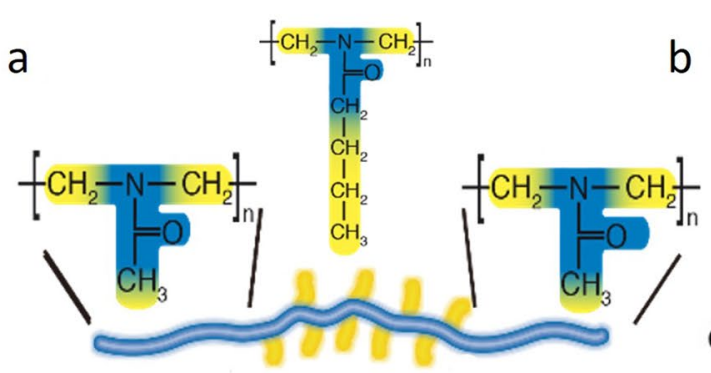

Polymer $=p M e O x-p B u O x-p M e O x$

d

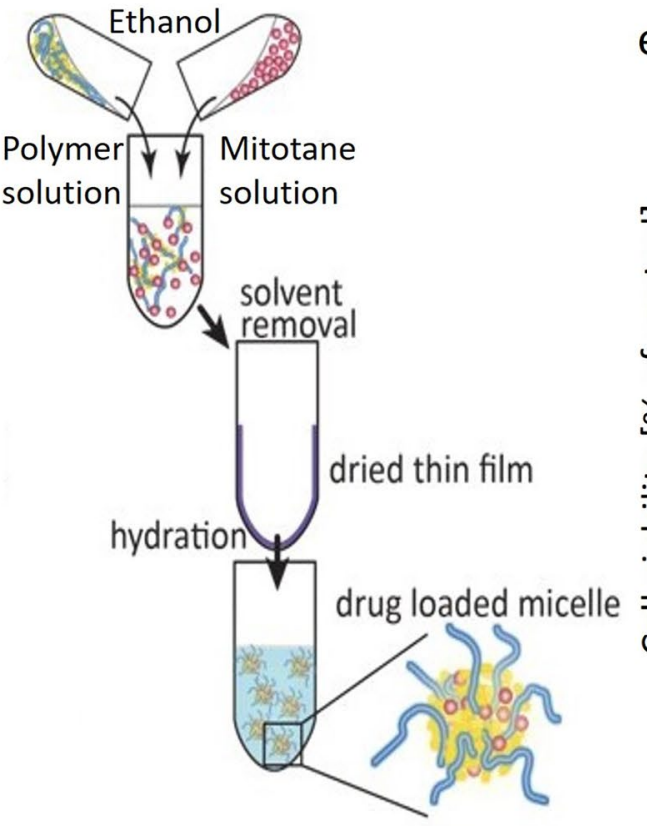

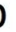<smiles>Clc1ccc(C(c2ccccc2Cl)C(Cl)Cl)cc1</smiles>

e

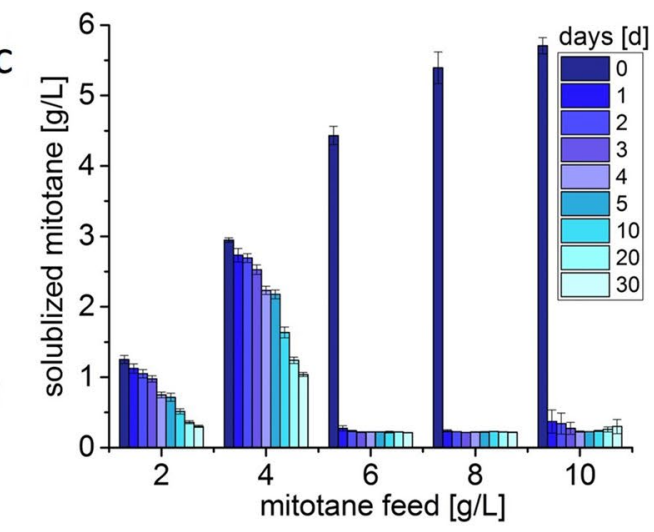

120 Monolayer Cell spheroids

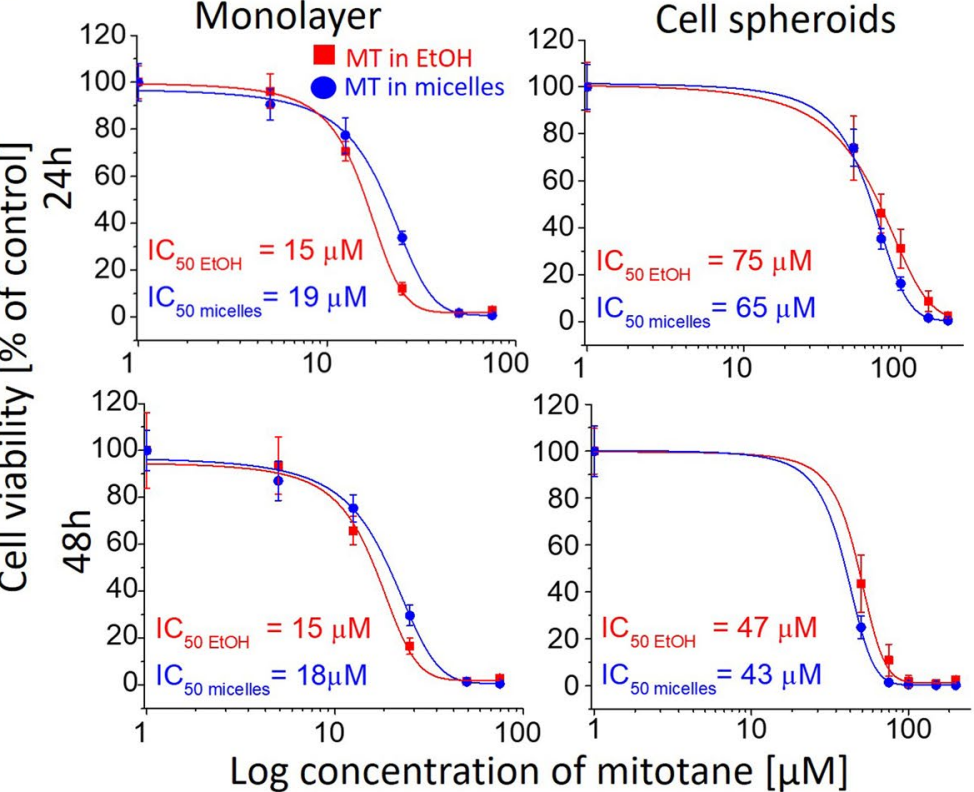

Fig. 9 a Schematic representation of polymer (pMeOx-b-pBuOxb-pMeOx) as best solubilizer for mitotane. b Chemical structure of mitotane. c Long-term stability of mitotane formulation depending on mitotane feed concentration (polymer $10 \mathrm{~g} / \mathrm{l}$, mitotane 2-10 g/l). Data are given as means $\pm \mathrm{SD}(n=3)$. d Schematic illustration of thin film hydration method used for formulation development. e Cell viability and corresponding $\mathrm{IC}_{50}$ values of mitotane dissolved in ethanol (red) and as micelle formulation (blue) in NCI-H295R monolayer after incubation for 24 and $48 \mathrm{~h}$ (left vertical panel) and 3D tumor spheroids at $24 \mathrm{~h}$ and 48 (right vertical panel) $(n=3 \pm \mathrm{SD})$. Modified with permission from [111] 
In case of 3D tumor spheroids, the $\mathrm{IC}_{50}$ values at $24 \mathrm{~h}$ were 75 and $65 \mu \mathrm{M}$ while a time-dependent decrease in $\mathrm{IC}_{50}$ values (at $48 \mathrm{~h}$ ) was observed (i.e., 47 and $43 \mu \mathrm{M}$ for mitotane in ethanol and POx micelles, respectively) (Fig. 9e). The pure polymer excipient was proven to be highly cytocompatible even at extremely high concentration of $100 \mathrm{~g} / \mathrm{l}$ in NCI-H295R and HepG2 cell lines (cell viability > 95\%). In general, POx-based amphiphiles have shown tremendous potential for formulation development [110, 112-117]. Utilizing the same amphiphile, i.e., pMeOx-pBuOx-pMeOx, Luxenhofer et al. previously reported the ultra-high paclitaxel -loaded formulations with the LC of $50 \mathrm{wt} \%$ [118]. The paclitaxel/pMeOx-pBuOx-pMeOx formulation showed superior antitumor efficacy (i.v. injection in mice) with a maximum tolerated dose (MTD) of $150 \mathrm{mg} / \mathrm{kg}$ compared to commercially available formulations, i.e., Taxol and Abraxane (MTD being 20 and $90 \mathrm{mg} / \mathrm{kg}$, respectively) [119]. Exploring further, Wan et al. reported an etoposide and hydrophobized cisplatin/pMeOx-b-pBuOx-b-pMeOx coformulation (i.v. injection in mice), which has demonstrated superior antitumor efficacy on various small cell and non-small cell lung cancer models compared to single formulations [120]. Very recently, Hwang et al. reported the vismodegib (VSM)/pMeOx-b-pBuOx-b-pMeOx formulation to overcome the off-target toxicities and resistance during treatment of medulloblastoma. When compared to conventional VSM, VSM/POx formulation (administered by oral gavage or IP injection) showed improved central nervous system pharmacokinetics and reduced systemic toxicity in transgenic mice engineered to develop endogenous medulloblastoma [121]. Concerning in vivo administration, the safety of the polymer excipient is of utmost importance. The cytocompatibility of POx-based amphiphiles has been repetitively established [111, 118, 122, 123], and the polymers are generally well tolerated at relevant doses after repeated injections.

For early and late stage disease patients, mitotane alone [124] or in combination with chemotherapeutic regimens including etoposide (E), doxorubicin (D) and cisplatin (P) (EDP-mitotane) has been established as standard treatment $[17,27,39,125]$. Attempts to find alternative strategies of ACC treatment [126, 127], e.g., by targeting cellular receptors involved in tumor growth and survival [128] like insulin-like growth factors receptors (IGF1 and IGF2) or vascular endothelial growth factor receptor (VEGFR) with targeted drugs like cixutumumab [129], linsitinib [130], bevacizumab plus capecitabine [131], sunitinib [132], thalidomide [133] and axitinib [134], have largely remained unsuccessful. However, with some drugs such as cabozantinib [135] minor clinical efficacy has been observed and these are now under further investigations [126]. Attempts utilizing improved formulations of cytostatic drugs have been reported. Hantel et al. investigated the therapeutic efficacy of EDP-mitotane compared to a paclitaxel modified scheme, i.e., paclitaxel, doxorubicin, cisplatin and mitotane (PDPmitotane) in in vitro and in vivo tumor models (NCIH-295R xenografts in NMRI nu/nu mice) [136]. In addition, liposomal variants of the similar regimen were also evaluated including liposomal doxorubicin [137], liposomal cisplatin and nanoparticle albumin bound paclitaxel (nab-PTX). In a mouse model, the liposomal formulations were administered intravenously (i.v.) while mitotane was dissolved in corn oil and injected intraperitoneally (i.p.). In vitro PDP-mitotane showed higher apoptotic and anti-proliferative effect while in vivo liposomal EDP-mitotane demonstrated sustained anti-tumoral effects. This study indicates that nanoformulations such as liposomal encapsulation of certain anticancer drugs in combination with mitotane could represent a promising treatment option for ACC [138]. Interestingly, drug

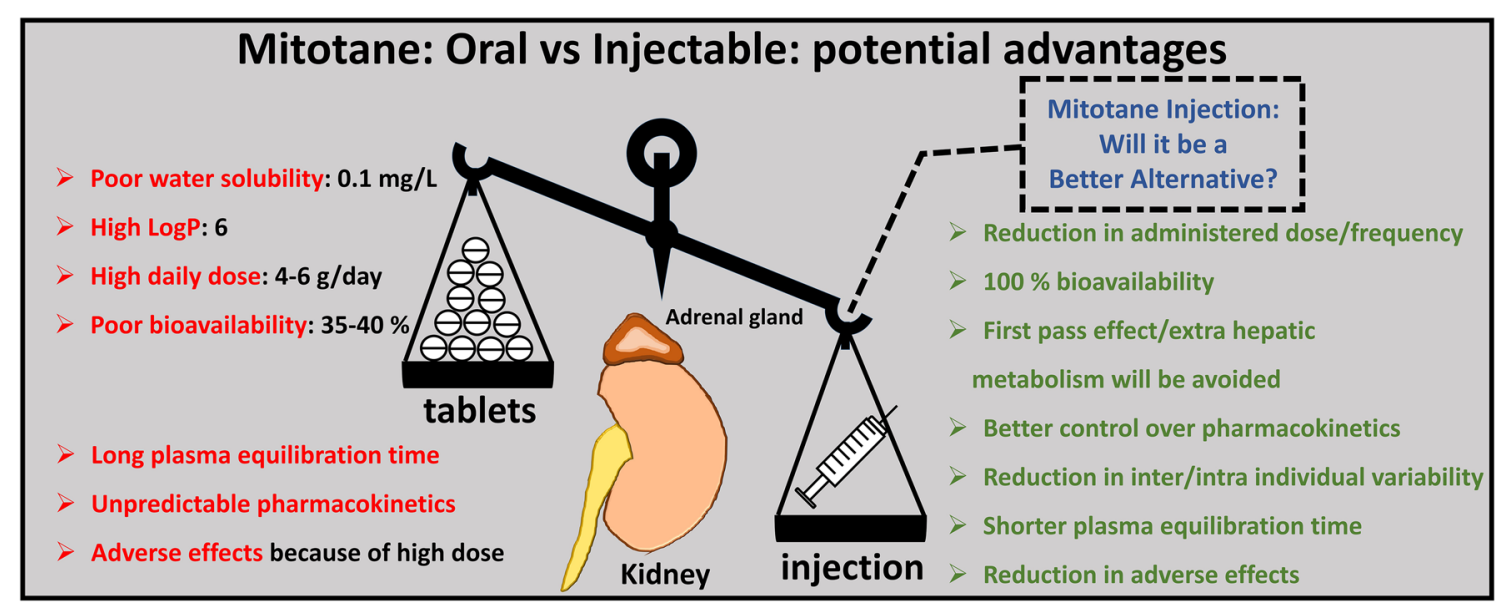

Scheme 1. Summary of mitotane potential advantages as injectable dosage form compared to oral 
combinations have been repeatedly established using a $\mathrm{POx}$ based polymer platform [139], which could potentially be utilized to realize mitotane-combination formulation, for example, novel combination formulations of the previously mentioned paclitaxel, doxorubicin, cisplatin with mitotane (PDP-mitotane).

An i.v. administration of POx-based mitotane formulation could be highly beneficial for several reasons (Scheme 1). First, we expect a significant reduction in the administered dose and potentially the dosing frequency (the usual dose is 4-6 g/day). The estimated bioavailability ranges from 30 to $40 \%$; thus, a dose reduction by up to $70 \%$ might be achievable, since i.v. infusion by definition yields $100 \%$ bioavailability. Because the absorption from the intestine is comparably slow, inefficient and subject to large IIV, an i.v. formulation would help to reduce the variability associated with mitotane pharmacokinetics and increase the patients' chance to reach the therapeutic target and therefore improve the clinical outcome. In addition, doing without oral administration potentially reduces gastrointestinal adverse reactions and reduces the amount of unabsorbed, unusable mitotane excreted with feces into the environment (roughly 3-4 g of polychlorinated aromatic compound per day!). Moreover, considering the poor bioavailability after oral administration, it can be hypothesized that the drug reaches the circulation slowly in comparably small increments, facilitating re-distribution into the excessively large volume of distribution $(161 \mathrm{l} / \mathrm{kg}$ lean body mass [72]). Furthermore, incorporation into chylomicrons should be reduced, again potentially affecting biodistribution. Finally, when injecting a comparably large amount i.v. in a single bolus, it can be assumed that redistribution is not immediate, and biodistribution and protein binding could be affected as previously described for paclitaxel formulated in the similar nanoformulations [123]. Hence, we postulate that the injected polymer micelles could avoid to some extent the predisposition of the drug to accumulate in the liver and other compartments or at least delay it. However, to assess this, thorough pharmacokinetic studies will be needed to better understand particularly the mitotane biodistribution after i.v. administration. Second, in the long term, higher patient compliance may be achievable if mitotane is administered intravenously at least during the initial phase of saturation. Currently, oral mitotane dose is limited by feasibility of administration which is up to 12 tablets daily.

Third, with an injectable mitotane, extra-hepatic metabolism in the intestine and/or chyle as well as first-pass effect will be avoided. In case of oral administration, the concentration of many drugs can significantly reduce before reaching systemic circulation. Such losses happen during absorption through the gut wall and/or first pass effect (exposition to liver for metabolism) while injectable mitotane could potentially avoid this issue. Fourth, we expect a drastic reduction in the time needed to achieve therapeutic plasma concentrations, possibly down to a few days, when adequate administration regimes could be applied. Finally, because i.v. application should overcome the IIV of absorption and first pass metabolism, we can anticipate a higher proportion of patients to attain therapeutic plasma concentrations. Response to monotherapy could be assessed with more confidence and hence this would potentially also reduce the proportion of patients who receive mitotane indefinitely. Accordingly, an improved therapeutic outcome with significantly improved quality of life for the patients may be within reach.

\section{Closing Remarks}

As there is lack of other compounds with antisecretory and antitumor activity, mitotane is the only drug used for the treatment of ACC. It is apparent that after 50 years of mitotane use in clinics and a large body of literature research, the safest and most effective use of mitotane may still not be established. This article provides an overview of the problems (i.e., first-pass metabolism, unpredictable pharmacokinetics profile, inter-individual variability, tissue accumulation and associated side effects, etc.) which can be directly correlated to the physico-chemical properties of mitotane and its route of administration. Additionally, a critical evaluation of the pharmaceutical advancements (with respect to dosage form development) is also provided along with the summary and outlook, i.e., the development of a mitotane injectable dosage form as a possible pharmaceutical intervention to circumvent these issues. We postulate, besides addressing these issues, the injectable mitotane formulation will also shorten the excessive lag time, which is the biggest problem of mitotane in the clinics. As previously discussed, as a proof of concept, recently we have reported on a POx-based mitotane micellar formulation which can potentially be used as an injectable formulation. Currently, this hypothesis is substantiated only from the side of formulation development, its extensive characterization and in vitro data; however, in vivo studies will be needed to prove our hypothesis. Currently, we are working on a protocol design and its implementation, which should address the specific issues of current mitotane treatment modalities. We hope that by developing an injectable mitotane formulation, an improved understanding of the pharmacokinetic properties, reduction in dose and adverse events might be possible, which would be important steps towards an improved ACC therapy. Additionally, the alternative administration will provide us with novel insights into the association of mitotane with serum LPs and potential changes in elimination half-life and tissue distribution. In the current scenario, where pharmaceutical industries are reluctant to invest in such a fragmented market of very little commercial interest [35, 37], scientists around 
the globe are nevertheless continuously working on various aspects of mitotane therapy. However, these efforts are yet to significantly impact the pharmacologic properties of the drug and improve efficacy and tolerability of mitotane for treatment of ACC.

\section{Declarations}

Funding Open Access funding enabled and organized by Projekt DEAL. Malik Salman Haider received a PhD scholarship from the Higher Education Commission of Pakistan and German Academic Exchange Services (HEC-DAAD Pakistan). This study was further supported by the German Research Foundation [Deutsche Forschungsgemeinschaft (DFG)], project number 314061271—CRC/TRR 205, to Matthias Kroiss.

Conflict of interest Matthias Kroiss declares that he has received travel support from HRA Pharma, the manufacturer of Lysodren ${ }^{\circledR}$ in Europe. Robert Luxenhofer is listed as an inventor of patents pertinent to some materials discussed in this contribution and co-founder of DelAqua Pharmaceutical Inc., which is intent on clinical development of poly(2oxazoline)-based drug formulations.

Ethics approval Not applicable.

Availability of data and material Not applicable.

Consent for publication Not applicable.

Code availability Not applicable.

Author contributions MSH had the conceptual idea for the article. The literature search was performed by MSH and TA. The first draft of the manuscript was written by MSH, and all authors commented on subsequent versions of manuscript and provided a critical revision for important intellectual content. All authors read and approved the final manuscript.

Open Access This article is licensed under a Creative Commons Attribution-NonCommercial 4.0 International License, which permits any non-commercial use, sharing, adaptation, distribution and reproduction in any medium or format, as long as you give appropriate credit to the original author(s) and the source, provide a link to the Creative Commons licence, and indicate if changes were made. The images or other third party material in this article are included in the article's Creative Commons licence, unless indicated otherwise in a credit line to the material. If material is not included in the article's Creative Commons licence and your intended use is not permitted by statutory regulation or exceeds the permitted use, you will need to obtain permission directly from the copyright holder. To view a copy of this licence, visit http://creativecommons.org/licenses/by-nc/4.0/.

\section{References}

1. Williams HD, Trevaskis NL, Charman SA, Shanker RM, Charman WN, Pouton CW, et al. Strategies to address low drug solubility in discovery and development. Pharmacol Rev. 2013;65(1):315-499.
2. Ali S, Kolter K. Challenges and opportunities in oral formulation development. Am Pharm Rev. 2012;15(7):1.

3. Homayun B, Lin X, Choi H-J. Challenges and recent progress in oral drug delivery systems for biopharmaceuticals. Pharmaceutics. 2019;11(3):129.

4. Kalepu S, Nekkanti V. Insoluble drug delivery strategies: review of recent advances and business prospects. Acta Pharm Sin B. 2015;5(5):442-53.

5. Fahr A, Liu X. Drug delivery strategies for poorly water-soluble drugs. Expert Opin Drug Deliv. 2007;4(4):403-16.

6. Pouton CW. Formulation of poorly water-soluble drugs for oral administration: physicochemical and physiological issues and the lipid formulation classification system. Eur J Pharm Sci. 2006;29(3-4):278-87.

7. Else T, Kim AC, Sabolch A, Raymond VM, Kandathil A, Caoili EM, et al. Adrenocortical carcinoma. Endocr Rev. 2013;35(2):282-326.

8. Hahner S, Fassnacht M. Mitotane for adrenocortical carcinoma treatment. Curr Opin Investig Drugs. 2005;6(4):386-94.

9. Biggar J, Riggs R. Apparent solubility of organochlorine insecticides in water at various temperatures. Hilgardia. 1974;42(10):383-91.

10. Moy R. Studies of the pharmacology of o, p'DDD in man. J Lab Clin Med. 1961;58:296-304.

11. Corso CR, Acco A, Bach C, Bonatto SJR, de Figueiredo BC, de Souza LM. Pharmacological profile and effects of mitotane in adrenocortical carcinoma. Br J Clin Pharmacol. 2020;87(7):2698-2710.

12. Xu W-H, Wu J, Wang J, Wan F-N, Wang H-K, Cao D-L, et al. Screening and identification of potential prognostic biomarkers in adrenocortical carcinoma. Front Genet. 2019;10:821.

13. Sharma E, Dahal S, Sharma P, Bhandari A, Gupta V, Amgai $\mathrm{B}$, et al. The characteristics and trends in adrenocortical carcinoma: a United States population based study. J Clin Med Res. 2018;10(8):636.

14. Berruti A, Baudin E, Gelderblom H, Haak H, Porpiglia F, Fassnacht M, et al. Adrenal cancer: ESMO Clinical Practice Guidelines for diagnosis, treatment and follow-up. Ann Oncol. 2012;23(suppl 7):vii131-8.

15. Kerkhofs TM, Verhoeven RH, Van der Zwan JM, Dieleman J, Kerstens MN, Links TP, et al. Adrenocortical carcinoma: a population-based study on incidence and survival in the Netherlands since 1993. Eur J Cancer. 2013;49(11):2579-86.

16. Veytsman I, Nieman L, Fojo T. Management of endocrine manifestations and the use of mitotane as a chemotherapeutic agent for adrenocortical carcinoma. J Clin Oncol. 2009;27(27):4619.

17. Fassnacht M, Allolio B. Clinical management of adrenocortical carcinoma. Best Pract Res Clin Endocrinol Metab. 2009;23(2):273-89.

18. Fassnacht M, Dekkers O, Else T, Baudin E, Berruti A, De Krijger RR, et al. European Society of Endocrinology Clinical Practice Guidelines on the management of adrenocortical carcinoma in adults, in collaboration with the European Network for the Study of Adrenal Tumors. Eur J Endocrinol. 2018;179(4):G1-46.

19. Mohan DR, Lerario AM, Hammer GD. Therapeutic targets for adrenocortical carcinoma in the genomics era. JES. 2018;2(11):1259-74.

20. Pereira SS, Monteiro MP, Costa MM, Moreira Â, Alves MG, Oliveira PF, et al. IGF2 role in adrenocortical carcinoma biology. Endocrine. 2019;66:326-37.

21. Guillaud-Bataille M, Ragazzon B, De Reynies A, Chevalier C, Francillard I, Barreau O, et al. IGF2 promotes growth of adrenocortical carcinoma cells, but its overexpression does not modify phenotypic and molecular features of adrenocortical carcinoma. PLoS ONE. 2014;9(8): e103744. 
22. Brown TC, Nicolson NG, Korah R, Carling T. BCL9 upregulation in adrenocortical carcinoma: a novel Wnt/ $\beta$-catenin activating event driving adrenocortical malignancy. J Am Coll Surg. 2018;226(6):988-95.

23. Assié G, Letouzé E, Fassnacht M, Jouinot A, Luscap W, Barreau $\mathrm{O}$, et al. Integrated genomic characterization of adrenocortical carcinoma. Nat Genet. 2014;46(6):607-12.

24. Zheng S, Cherniack AD, Dewal N, Moffitt RA, Danilova L, Murray $\mathrm{BA}$, et al. Comprehensive pan-genomic characterization of adrenocortical carcinoma. Cancer Cell. 2016;29(5):723-36.

25. Wang W, Han R, Ye L, Xie J, Tao B, Sun F, et al. Adrenocortical carcinoma in patients with MEN1: a kindred report and review of the literature. Endocr Connect. 2019;8(3):230-8.

26. Schteingart D, Doherty G, Gauger P, Giordano T, Hammer G, Korobkin M, et al. Management of patients with adrenal cancer: Recommendations of an international consensus conference. Endocr-Relat Cancer. 2005;12(3):667-80.

27. Fassnacht M, Terzolo M, Allolio B, Baudin E, Haak H, Berruti A, et al. Combination chemotherapy in advanced adrenocortical carcinoma. N Engl J Med. 2012;366(23):2189-97.

28. Fassnacht M, Libé R, Kroiss M, Allolio B. Adrenocortical carcinoma: a clinician's update. Nat Rev Endocrinol. 2011;7(6):323.

29. Pennanen M, Heiskanen I, Sane T, Remes S, Mustonen H, Haglund C, et al. Helsinki score-a novel model for prediction of metastases in adrenocortical carcinomas. Hum Pathol. 2015;46(3):404-10.

30. Cueto C, Brown J. Biological studies on an adrenocorticolytic agent and the isolation of the active components. Endocrinology. 1958;62(3):334-9.

31. Cueto C, Brown J. The chemical fractionation of an adrenocorticolytic drug. Endocrinology. 1958;62(3):326-33.

32. Cazaubon Y, Talineau Y, Feliu C, Konecki C, Russello J, Mathieu $\mathrm{O}$, et al. Population pharmacokinetics modelling and simulation of mitotane in patients with adrenocortical carcinoma: an individualized dose regimen to target all patients at three months? Pharmaceutics. 2019;11(11):566.

33. Postlewait LM, Ethun CG, Tran TB, Prescott JD, Pawlik TM, Wang TS, et al. Outcomes of adjuvant mitotane after resection of adrenocortical carcinoma: a 13-institution study by the US Adrenocortical Carcinoma Group. J Am Coll Surg. 2016;222(4):480-90.

34. Berruti A, Grisanti S, Pulzer A, Claps M, Daffara F, Loli P, et al. Long-term outcomes of adjuvant mitotane therapy in patients with radically resected adrenocortical carcinoma. J Clin Endocrinol Metab. 2017;102(4):1358-65.

35. Joppi R, Bertele V, Garattini S. Orphan drug development is progressing too slowly. Br J Clin Pharmacol. 2006;61(3):355-60.

36. European Medicine Agency Website. https://www.ema.europa. eu/en/medicines/human/orphan-designations/eu302102. Accessed 26 Jun 2021.

37. Joppi R, Bertele V, Garattini S. Orphan drug development is not taking off. Br J Clin Pharmacol. 2009;67(5):494-502.

38. Terzolo M, Daffara F, Ardito A, Zaggia B, Basile V, Ferrari L, et al. Management of adrenal cancer: a 2013 update. J Endocrinol Investig. 2014;37(3):207-17.

39. Calabrese A, Puglisi S, Basile V, Perotti P, Terzolo M. Mitotane: new facts for an old drug. Curr Opinion Endocr Metab Res. 2019;8:145-51.

40. Zsippai A, Szabó DR, Tömböl Z, Szabó PM, Éder K, Pállinger É, et al. Effects of mitotane on gene expression in the adrenocortical cell line NCI-H295R: a microarray study. Pharmacogenomics. 2012;13(12):1351-61.

41. Stigliano A, Cerquetti L, Borro M, Gentile G, Bucci B, Misiti $\mathrm{S}$, et al. Modulation of proteomic profile in H295R adrenocortical cell line induced by mitotane. Endocr-Relat Cancer. 2008;15(1):1
42. Brown RD, Nicholson WE, Chick WT, Strott CA. Effect of o,p'DDD on human adrenal steroid 11 $\beta$-hydroxylation activity. J Clin Endocrinol Metab. 1973;36(4):730-3.

43. Van Koetsveld PM, Vitale G, Feelders RA, Waaijers M, SprijMooij DM, De Krijger RR, et al. Interferon-b is a potent inhibitor of cell growth and cortisol production in vitro and sensitizes human adrenocortical carcinoma cells to mitotane. Endocr-Relat Cancer. 2013;20:443-54.

44. Lehmann TP, Wrzesiński T, Jagodziński PP. The effect of mitotane on viability, steroidogenesis and gene expression in NCIH295R adrenocortical cells. Mol Med Rep. 2013;7(3):893-900.

45. Poli G, Guasti D, Rapizzi E, Fucci R, Canu L, Bandinelli A, et al. Morphofunctional effects of mitotane on mitochondria in human adrenocortical cancer cells. Endocr-Relat Cancer. 2013;20(4):537-50.

46. Sbiera S, Leich E, Liebisch G, Sbiera I, Schirbel A, Wiemer $\mathrm{L}$, et al. Mitotane inhibits sterol-O-acyl transferase 1 triggering lipid-mediated endoplasmic reticulum stress and apoptosis in adrenocortical carcinoma cells. Endocrinology. 2015;156(11):3895-908.

47. Sbiera S, Wiemer L, Leich E, Gehl A, Gardill F, Ronchi CL, et al. Mitotane induces endoplasmic reticulum stress triggering apoptosis and decrease of steroid hormone synthesis. Exp Clin Endocrinol Diabetes. 2014;122:P019.

48. Weigand I, Altieri B, Lacombe AM, Basile V, Kircher S, Landwehr L-S, et al. Expression of SOAT1 in adrenocortical carcinoma and response to mitotane monotherapy: an ENSAT multicenter study. J Clin Endocrinol Metab. 2020;105(8):2642-53.

49. Lalli E. Mitotane revisited: a new target for an old drug. Endocrinology. 2015;156(11):3873-5.

50. Lacombe AMF, Soares IC, Charchar HDS, Brondani VB, Neto JEB, Tanno F, et al. SAT-165 sterol O-acyl transferase 1 as a prognostic marker of adrenocortical carcinoma. Cancers. 2020;4(12):247.

51. Holmes D. Cancer target of mitotane identified. Nat Rev Endocrinol. 2015;11(11):631.

52. Paragliola RM, Torino F, Papi G, Locantore P, Pontecorvi A, Corsello SM. Role of mitotane in adrenocortical carcinomareview and state of the art. Eur Endocrinol. 2018;14(2):62-6.

53. Puglisi S, Calabrese A, Basile V, Pia A, Reimondo G, Perotti P, et al. New perspectives for mitotane treatment of adrenocortical carcinoma. Best Pract Res Clin Endocrinol Metab. 2020;34(3): 101415.

54. Moolenaar A, Van Slooten H, Van Seters A, Smeenk D. Blood levels of $\mathrm{o}, \mathrm{p}^{\prime}$-DDD following administration in various vehicles after a single dose and during long-term treatment. Cancer Chemother Pharmacol. 1981;7(1):51-4.

55. Grid'ko A, Borzunov E, Komissarenko I, Perepelitsa N. Pharmacokinetics of chlodithane tablets in the treatment of Cushing's syndrome. Probl Endokrnol. 1981;27(2):32-5.

56. Hermansson V, Cantillana T, Hovander L, Bergman Å, Ljungvall $\mathrm{K}$, Magnusson $\mathrm{U}$, et al. Pharmacokinetics of the adrenocorticolytic compounds 3-methylsulphonyl-DDE and o, $\mathrm{p}^{\prime}$-DDD (mitotane) in Minipigs. Cancer Chemother Pharmacol. 2008;61(2):267-74.

57. Martz F, Straw JA. The in vitro metabolism of 1-(o-chlorophenyl)1-(p-chlorophenyl)-2, 2-dichloroethane (o, p'-DDD) by dog adrenal mitochondria and metabolite covalent binding to mitochondrial macromolecules: a possible mechanism for the adrenocorticolytic effect. Drug Metab Dispos. 1977;5(5):482-6.

58. Lund B-O, Bergman $\AA$, Brandt I. In vitro macromolecular binding of 2-(2-chlorophenyl)-2-(4-chlorophenyl)-1, 1-dichloroethane $\left(\mathrm{o}, \mathrm{p}^{\prime}\right.$-DDD) in the mouse lung and liver. Chem Biol Interact. 1989;70(1-2):63-72.

59. Cai W, Counsell R, Djanegara T, Schteingart D, Sinsheimer J, Wotring L. Metabolic activation and binding of mitotane in adrenal cortex homogenates. J Pharm Sci. 1995;84(2):134-8. 
60. Mornar A, Sertić M, Turk N, Nigović B, Koršić M. Simultaneous analysis of mitotane and its main metabolites in human blood and urine samples by SPE-HPLC technique. Biomed Chromatogr. 2012;26(11):1308-14.

61. Chu S, Covaci A, Jacobs W, Haraguchi K, Schepens P. Distribution of methyl sulfone metabolites of polychlorinated biphenyls and p, p'-DDE in human tissues. Environ Health Perspect. 2003;111(9):1222-7.

62. Finnegan J, Haag H, Larson P. Tissue distribution and elimination of DDD and DDT following oral administration to dogs and rats. SEBM. 1949;72(2):357-60.

63. Kroiss M, Plonné D, Kendl S, Schirmer D, Ronchi CL, Schirbel A, et al. Association of mitotane with chylomicrons and serum lipoproteins: practical implications for treatment of adrenocortical carcinoma. Eur J Endocrinol. 2016;174(3):343-53.

64. Allegra S, Puglisi S, Brescia I, Chiara F, Basile V, Calabrese A, et al. Sex differences on mitotane concentration and treatment outcome in patients with adrenocortical carcinoma. Life. 2021;11(3):266.

65. Jančić-Stojanović B, Vemić S, Elezović V, Petrović A, Sinadinović Z, Ivanović D, et al. Development of new liquid chromatographic method for mitotane and its metabolites determination in human plasma employing design of experiments methodology. J Liq Chrom Relat Tech. 2015;38(14):1371-8.

66. Garg MB, Sakoff JA, Ackland SP. A simple HPLC method for plasma level monitoring of mitotane and its two main metabolites in adrenocortical cancer patients. J Chromatogr B. 2011;879(23):2201-5.

67. Asp V, Cantillana T, Bergman $̊$, Brandt I. Chiral effects in adrenocorticolytic action of o, $\mathrm{p}^{\prime}$-DDD (mitotane) in human adrenal cells. Xenobiotica. 2010;40(3):177-83.

68. Gebhardt D, Moolenaar A, Seters VA, Van Der Velde E, Leuven JG. The distribution of o, p'-DDD (Mitotane) among serum lipoproteins in normo-and hypertriglyceridemia. Cancer Chemother Pharmacol. 1992;29(4):331-4.

69. Pohland RC, Counsell RE. The role of high density lipoproteins in the biodistribution of two radioiodinated probes in the rat. Toxicol Appl Pharmacol. 1985;77(1):47-57.

70. Hescot S, Seck A, Guerin M, Cockenpot F, Huby T, Broutin $\mathrm{S}$, et al. Lipoprotein-free mitotane exerts high cytotoxic activity in adrenocortical carcinoma. J Clin Endocrinol Metab. 2015;100(8):2890-8.

71. Hescot S, Paci A, Seck A, Slama A, Viengchareun S, Trabado $\mathrm{S}$, et al. The lack of antitumor effects of o, p' DDA excludes its role as an active metabolite of mitotane for adrenocortical carcinoma treatment. Horm Cancer. 2014;5(5):312-23.

72. Kerkhofs TM, Derijks LJ, Ettaieb H, Den Hartigh J, Neef K, Gelderblom H, et al. Development of a pharmacokinetic model of mitotane: toward personalized dosing in adrenocortical carcinoma. Ther Drug Monit. 2015;37(1):58-65.

73. Arshad U, Taubert M, Kurlbaum M, Frechen S, Herterich $\mathrm{S}$, Megerle F, et al. Enzyme autoinduction by mitotane supported by population pharmacokinetic modelling in a large cohort of adrenocortical carcinoma patients. Eur J Endocrinol. 2018;179(5):287-97.

74. Theile D, Haefeli WE, Weiss J. Effects of adrenolytic mitotane on drug elimination pathways assessed in vitro. Endocrine. 2015;49(3):842-53.

75. Sinz MW. Evaluation of pregnane $X$ receptor (PXR)-mediated CYP3A4 drug-drug interactions in drug development. Drug Metab Rev. 2013;45(1):3-14.

76. Watson A, Rijnberk A, Moolenaar A. Systemic availability of o, p'-DDD in normal dogs, fasted and fed, and in dogs with hyperadrenocorticism. Res Vet Sci. 1987;43(2):160-5.

77. Hermsen IG, Fassnacht M, Terzolo M, Houterman S, den Hartigh J, Leboulleux S, et al. Plasma concentrations of o, p' DDD, $\mathrm{o}, \mathrm{p}^{\prime} \mathrm{DDA}$, and o, $\mathrm{p}^{\prime}$ DDE as predictors of tumor response to mitotane in adrenocortical carcinoma: results of a retrospective ENS@T multicenter study. J Clin Endocrinol Metab. 2011;96(6):1844-51.

78. Terzolo M, Baudin A, Ardito A, Kroiss M, Leboulleux S, Daffara F, et al. Mitotane levels predict the outcome of patients with adrenocortical carcinoma treated adjuvantly following radical resection. Eur J Endocrinol. 2013;169(3):263-70.

79. Megerle F, Herrmann W, Schloetelburg W, Ronchi CL, Pulzer A, Quinkler M, et al. Mitotane monotherapy in patients with advanced adrenocortical carcinoma. J Clin Endocrinol Metab. 2018;103(4):1686-95.

80. Kitamura S, Shimizu Y, Shiraga Y, Yoshida M, Sugihara K, Ohta $\mathrm{S}$. Reductive metabolism of $\mathrm{p}, \mathrm{p}^{\prime}$-DDT and $\mathrm{o}, \mathrm{p}^{\prime}$-DDT by rat liver cytochrome P450. Drug Metab Dispos. 2002;30(2):113-8.

81. van Erp NP, Guchelaar HJ, Ploeger BA, Romijn JA, den Hartigh $\mathrm{J}$, Gelderblom H. Mitotane has a strong and a durable inducing effect on CYP3A4 activity. Eur J Endocrinol. 2011;164(4):621-6.

82. Yin A, Ettaieb MH, Swen JJ, van Deun L, Kerkhofs TM, van der Straaten RJ, et al. Population pharmacokinetic and pharmacogenetic analysis of mitotane in patients with adrenocortical carcinoma: towards individualized dosing. Clin Pharmacokinet. 2020;60:1-14.

83. Arshad U, Taubert M, Kurlbaum M, Frechen S, Herterich $\mathrm{S}$, Megerle F, et al. Enzyme autoinduction by mitotane supported by population pharmacokinetic modeling in a large cohort of adrenocortical carcinoma patients. Eur J Endocrinol. 2018;179(5):287-97.

84. Haak H, Hermans J, Van de Velde C, Lentjes E, Goslings B, Fleuren G, et al. Optimal treatment of adrenocortical carcinoma with mitotane: results in a consecutive series of 96 patients. Br J Cancer. 1994;69(5):947.

85. Kerkhofs T, Baudin E, Terzolo M, Allolio B, Chadarevian R, Mueller $\mathrm{H}$, et al. Comparison of two mitotane starting dose regimens in patients with advanced adrenocortical carcinoma. J Clin Endocrinol Metab. 2013;98(12):4759-67.

86. Puglisi S, Calabrese A, Basile V, Ceccato F, Scaroni C, Altieri $\mathrm{B}$, et al. Mitotane concentrations influence outcome in patients with advanced adrenocortical carcinoma. Cancers. 2020;12(3):740.

87. Faggiano A, Leboulleux S, Young J, Schlumberger M, Baudin E. Rapidly progressing high o, p'DDD doses shorten the time required to reach the therapeutic threshold with an acceptable tolerance: preliminary results. Clin Endocrinol. 2006;64(1):110-3.

88. Neuman O, Bruckert E, Chadarevian R, Jacob N, Turpin G. Hepatotoxicity of a synthetic cortisol antagonist: OP'DDD (mitotane). Therapie. 2001;56(6):793-7.

89. Shawa H, Deniz F, Bazerbashi H, Hernandez M, VassilopoulouSellin R, Jimenez C, et al. Mitotane-induced hyperlipidemia: a retrospective cohort study. Int J Endocrinol. 2013;2013:1-7.

90. Oddie PD, Albert BB, Hofman PL, Jefferies C, Laughton S, Carter PJ. Mitotane in the treatment of childhood adrenocortical carcinoma: a potent endocrine disruptor. Endocrinol Diabetes Metab Case Rep. 2018, 18-0059.

91. Pape E, Feliu C, Yéléhé-Okouma M, Colling N, Djerada Z, Gambier N, et al. High-dose mitotane-induced encephalopathy in the treatment of adrenocortical carcinoma. Oncologist. 2018;23(3):389.

92. Goto T, Miyako K, Kuromaru R, Ihara K, Torisu H, Sanefuji M, et al. Case report: adjuvant therapy with a high dose of mitotane for adrenocortical carcinoma in a 4-year-old boy. Clin Pediatr Endocrinol. 2008;17(3):71-4.

93. Russo M, Scollo C, Pellegriti G, Cotta OR, Squatrito S, Frasca $\mathrm{F}$, et al. Mitotane treatment in patients with adrenocortical cancer causes central hypothyroidism. Clin Endocrinol. 2016;84(4):614-9. 
94. Friedl B, Kurlbaum M, Kroiss M, Fassnacht M, Scherf-Clavel O. A method for the minimally invasive drug monitoring of mitotane by means of volumetric absorptive microsampling for a home-based therapeutic drug monitoring. Anal Bioanal Chem. 2019;411(17):3951-62.

95. Takano R, Furumoto K, Shiraki K, Takata N, Hayashi Y, Aso Y, et al. Rate-limiting steps of oral absorption for poorly watersoluble drugs in dogs; prediction from a miniscale dissolution test and a physiologically-based computer simulation. Pharm Res. 2008;25(10):2334-44.

96. Slooten HV, Van Seters A, Smeenk D, Moolenaar A. O, p'-DDD (mitotane) levels in plasma and tissues during chemotherapy and at autopsy. Cancer Chemother Pharmacol. 1982;9(2):85-8.

97. Lin Y-H, Chen Y-S, Wu T-C, Chen L-J. Enhancement of dissolution rate of mitotane and warfarin prepared by using microemulsion systems. Colloids Surf. 2011;85(2):366-72.

98. Attivi D, Ajana I, Astier A, Demore B, Gibaud S. Development of microemulsion of mitotane for improvement of oral bioavailability. Drug Dev Ind Pharm. 2010;36(4):421-7.

99. Battung F, Hassan E, Sansoe L. US8486445B2; 2013.

100. Trotta M, Gallarate M, Pattarino F, Morel S. Emulsions containing partially water-miscible solvents for the preparation of drug nanosuspensions. J Control Release. 2001;76(1-2):119-28.

101. Menaa F, Menaa B. Development of mitotane lipid nanocarriers and enantiomers: two-in-one solution to efficiently treat adrenocortical carcinoma. Curr Med Chem. 2012;19(34):5854-62.

102. Cantillana T, Lindström V, Eriksson L, Brandt I, Bergman $\AA$. Interindividual differences in o, p'-DDD enantiomer kinetics examined in Göttingen minipigs. Chemosphere. 2009;76(2):167-72.

103. Antelo F, Santana CC, Moitinho Alves TL, Barreto AG Jr. Thermodynamic study of enantioseparation of mitotane by supercritical fluid chromatography. Sep Sci Technol. 2012;47(4):636-40.

104. Severino P, Souto EB, Pinho SC, Santana MH. Hydrophilic coating of mitotane-loaded lipid nanoparticles: preliminary studies for mucosal adhesion. Pharm Dev Technol. 2013;18(3):577-81.

105. Grando CRC, Guimarães CA, Mercuri LP, Matos JDR, Santana MHA. Preparation and characterization of solid lipid nanoparticles loaded with racemic mitotane. J Colloid Sci Biotechnol. 2013;2(2):140-5.

106. Alfonsi R, Attivi D, Astier A, Socha M, Morice S, Gibaud S. Characterization of mitotane (o, $\mathrm{p}^{\prime}$-DDD)-cyclodextrin inclusion complexes: phase-solubility method and NMR. Ann Pharm Fr. 2013;71(3):186-92.

107. Zancanella P, Oliveira D, de Oliveira B, Woiski T, Pinto C, Santana M, et al. Mitotane liposomes for potential treatment of adrenal cortical carcinoma: ex vivo intestinal permeation and in vivo bioavailability. Pharm Dev Technol. 2020;25(8):1-36.

108. Naguib YW, O'Mary HL, Cui Z, Watts AB. Injectable formulations of poorly water-soluble drugs. Formulating poorly water soluble drugs. New York: Springer; 2016. p. 257-93.

109. Kuentz M, Holm R, Elder DP. Methodology of oral formulation selection in the pharmaceutical industry. Eur J Pharm Sci. 2016;87:136-63.

110. Lorson T, Lübtow MM, Wegener E, Haider MS, Borova S, Nahm D, et al. Poly (2-oxazoline)s based biomaterials: a comprehensive and critical update. Biomaterials. 2018;178:204-80.

111. Haider MS, Schreiner J, Kendl S, Kroiss M, Luxenhofer R. A micellar mitotane formulation with high drug-loading and solubility: physico-chemical characterization and cytotoxicity studies in 2D and 3D in vitro tumor models. Macromol Biosci. 2020;20(1): 1900178 .

112. Lübtow MM, Nelke LC, Seifert J, Kühnemundt J, Sahay G, Dandekar G, et al. Drug induced micellization into ultra-high capacity and stable curcumin nanoformulations: physico-chemical characterization and evaluation in $2 \mathrm{D}$ and $3 \mathrm{D}$ in vitro models. $\mathrm{J}$ Control Release. 2019;303:162-80.

113. Lübtow MM, Haider MS, Kirsch M, Klisch S, Luxenhofer R. Like dissolves like? A comprehensive evaluation of partial solubility parameters to predict polymer-drug compatibility in ultra-high drug loaded polymer micelles. Biomacromol. 2019;20:3041-56.

114. Hahn L, Lübtow MM, Lorson T, Schmitt F, Appelt-Menzel A, Schobert R, et al. Investigating the influence of aromatic moieties on the formulation of hydrophobic natural products and drugs in poly (2-oxazoline)-based amphiphiles. Biomacromol. 2018;19(7):3119-28.

115. Lübtow MM, Hahn L, Haider MS, Luxenhofer R. Drug specificity, synergy and antagonism in ultrahigh capacity poly (2-oxazoline)/poly (2-oxazine) based formulations. J Am Chem Soc. 2017;139(32):10980-3.

116. Seo Y, Schulz A, Han Y, He Z, Bludau H, Wan X, et al. Poly (2-oxazoline) block copolymer based formulations of taxanes: effect of copolymer and drug structure, concentration, and environmental factors. Polym Adv Technol. 2015;26(7):837-50.

117. Lübtow MM, Oerter S, Quader S, Jeanclos E, Cubukova A, Krafft $\mathrm{M}$, et al. In vitro blood-brain barrier permeability and cytotoxicity of an atorvastatin-loaded nanoformulation against glioblastoma in 2D and 3D models. Mol Pharm. 2020;17(6):1835-47.

118. Luxenhofer R, Schulz A, Roques C, Li S, Bronich TK, Batrakova EV, et al. Doubly amphiphilic poly (2-oxazoline)s as highcapacity delivery systems for hydrophobic drugs. Biomaterials. 2010;31(18):4972-9.

119. He Z, Schulz A, Wan X, Seitz J, Bludau H, Alakhova DY, et al. Poly (2-oxazoline) based micelles with high capacity for 3rd generation taxoids: preparation, in vitro and in vivo evaluation. J Control Release. 2015;208:67-75.

120. Wan X, Min Y, Bludau H, Keith A, Sheiko SS, Jordan R, et al. Drug combination synergy in worm-like polymeric micelles improves treatment outcome for small cell and non-small cell lung cancer. ACS Nano. 2018;12(3):2426-39.

121. Hwang D, Dismuke T, Tikunov A, Rosen E, Kagel J, Ramsey $\mathrm{J}$, et al. Poly (2-oxazoline) nanoparticle delivery enhances the therapeutic potential of vismodegib for medulloblastoma by improving CNS pharmacokinetics and reducing systemic toxicity. Nanomedicine. 2020;32:102345.

122. Luxenhofer R, Sahay G, Schulz A, Alakhova D, Bronich TK, Jordan R, et al. Structure-property relationship in cytotoxicity and cell uptake of poly (2-oxazoline) amphiphiles. J Control Release. 2011;153(1):73-82.

123. He Z, Wan X, Schulz A, Bludau H, Dobrovolskaia MA, Stern ST, et al. A high capacity polymeric micelle of paclitaxel: implication of high dose drug therapy to safety and in vivo anti-cancer activity. Biomaterials. 2016;101:296-309.

124. Reidy-Lagunes DL, Lung B, Untch BR, Raj N, Hrabovsky A, Kelly C, et al. Complete responses to mitotane in metastatic adrenocortical carcinoma- a new look at an old drug. Oncologist. 2017;22(9):1102.

125. De Filpo G, Mannelli M, Canu L. Adrenocortical carcinoma: current treatment options. Curr Opin Oncol. 2021;33(1):16-22.

126. Altieri B, Ronchi CL, Kroiss M, Fassnacht M. Next-generation therapies for adrenocortical carcinoma. Best Pract Res Clin Endocrinol Metab. 2020;34(3):101434.

127. Vincent A, Marie-Eve G, Rossella L, Thierry B, Yves R, Frederic C. Medical management of adrenocortical carcinoma: current recommendations, new therapeutic options and future perspectives. Ann Endocrinol. 2021;82(1):52-8.

128. Hallanger-Johnson JE. Systemic therapy for adrenocortical carcinoma: a review. AME Med J. 2020;5(5):5.

129. Lerario AM, Worden FP, Ramm CA, Hasseltine EA, Stadler WM, Else T, et al. The combination of insulin-like growth factor 
receptor 1 (IGF1R) antibody cixutumumab and mitotane as a first-line therapy for patients with recurrent/metastatic adrenocortical carcinoma: a multi-institutional NCI-sponsored trial. Horm Cancer. 2014;5(4):232-9.

130. Fassnacht M, Berruti A, Baudin E, Demeure MJ, Gilbert J, Haak H, et al. Linsitinib (OSI-906) versus placebo for patients with locally advanced or metastatic adrenocortical carcinoma: a double-blind, randomised, phase 3 study. Lancet Oncol. 2015;16(4):426-35.

131. Wortmann S, Quinkler M, Ritter C, Kroiss M, Johanssen S, Hahner $\mathrm{S}$, et al. Bevacizumab plus capecitabine as a salvage therapy in advanced adrenocortical carcinoma. Eur J Endocrinol. 2010;162(2):349.

132. Kroiss M, Quinkler M, Johanssen S, van Erp NP, Lankheet N, Pöllinger A, et al. Sunitinib in refractory adrenocortical carcinoma: a phase II, single-arm, open-label trial. J Clin Endocrinol Metab. 2012;97(10):3495-503.

133. Kroiss M, Deutschbein T, Schlötelburg W, Ronchi CL, Hescot S, Körbl D, et al. Treatment of refractory adrenocortical carcinoma with thalidomide: Analysis of 27 patients from the European Network for the Study of Adrenal Tumours Registry. Exp Clin Endocrinol Diabetes. 2019;127(09):578-84.

134. O'Sullivan C, Edgerly M, Velarde M, Wilkerson J, Venkatesan AM, Pittaluga S, et al. The VEGF inhibitor axitinib has limited effectiveness as a therapy for adrenocortical cancer. J Clin Endocrinol Metab. 2014;99(4):1291-7.

135. Kroiss M, Megerle F, Kurlbaum M, Zimmermann S, Wendler $\mathrm{J}$, Jimenez C, et al. Objective response and prolonged disease control of advanced adrenocortical carcinoma with cabozantinib. J Clin Endocrinol Metab. 2020;105(5):1461-8.

136. Hantel C, Jung S, Mussack T, Reincke M, Beuschlein F. Liposomal polychemotherapy improves adrenocortical carcinoma treatment in a preclinical rodent model. Endocr-Relat Cancer. 2014;21(3):383-94.

137. Hantel C, Lewrick F, Reincke M, Süss R, Beuschlein F. Liposomal doxorubicin-based treatment in a preclinical model of adrenocortical carcinoma. J Endocrinol. 2012;213(2):155.

138. Jung S, Nagy Z, Fassnacht M, Zambetti G, Weiss M, Reincke M, et al. Preclinical progress and first translational steps for a liposomal chemotherapy protocol against adrenocortical carcinoma. Endocr-Relat Cancer. 2016;23(10):825-37.

139. Wan X, Beaudoin JJ, Vinod N, Min Y, Makita N, Bludau H, et al. Co-delivery of paclitaxel and cisplatin in poly (2-oxazoline) polymeric micelles: implications for drug loading, release, pharmacokinetics and outcome of ovarian and breast cancer treatments. Biomaterials. 2019;192:1-14. 